PONTIFÍCIA UNIVERSIDADE CATÓLICA DO RIO DE JANEIRO

\title{
Avaliação Econômico-Financeira de uma Termelétrica no Brasil: um estudo de caso da Itaqui Geração de Energia S.A.
}

Karine de Oliveira Santos

Trabalho de Conclusão de Curso

Centro de CIÊnCIAS SOCIAIS - CCS

DEPARTAMENTO DE AdMINISTRAÇÃO

Graduação em Administração de Empresas 


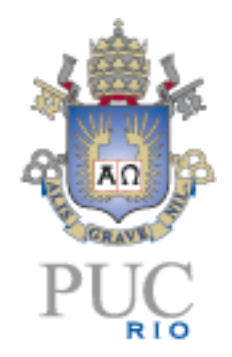

Karine de Oliveira Santos

Avaliação Econômico-Financeira de uma Termelétrica no Brasil: um estudo de caso da Itaqui Geração de Energia S.A..

Trabalho de Conclusão de Curso

Trabalho de Conclusão de Curso, apresentado ao programa de graduação em Administração da PUC-Rio como requisito parcial para a obtenção do título de graduação em Administração.

Rio de Janeiro, junho de 2016. 


\section{Agradecimentos}

Primeiramente, agradeço ao meu grandioso Deus por estar comigo durante todo o tempo. Nos momentos mais difíceis percebemos o quão importante e valioso é ter fé em Deus e uma base na qual podemos nos apoiar quando o cansaço começa a pesar.

Agradeço imensamente aos meus pais, Kleber e Janete, a meu irmão, Renan, e à minha linda família pelo apoio, por todos os conselhos e, principalmente, por me motivarem a prosseguir.

Agradeço ao meu amigo e namorado, Gonzalo, pelo apoio e compreensão nessa etapa tão importante da minha carreira.

Agradeço a PUC por me proporcionar quatro anos e meio de riquíssimo aprendizado e a todos os professores que estiveram presentes nessa caminhada, em particular, ao meu orientador, Rafael Igrejas. 


\section{Resumo}

Santos, Karine de Oliveira. Avaliação Econômico-Financeira de uma Termelétrica no Brasil: um estudo de caso da Itaqui Geração de Energia S.A.. Rio de Janeiro, 2016. 49 p. Trabalho de Conclusão de Curso Departamento de Administração. Pontifícia Universidade Católica do Rio de Janeiro.

O presente estudo tem como objetivo realizar uma avaliação econômicofinanceira de um ativo através de uma aplicação do método de fluxo de caixa descontado. O ativo em questão é uma usina termelétrica movida a carvão, localizada no Nordeste do Brasil.

Esta avaliação consiste em abordar as principais características da elaboração de um fluxo de caixa descontado, analisar os indicadores financeiros históricos do ativo e realizar uma breve análise de como as termelétricas atuam no cenário brasileiro.

A avaliação da usina de Itaqui proposta nesse estudo, tem como objetivo final servir como ferramenta de apoio para auxiliar nas tomadas de decisões econômicas e financeiras da controladora da usina, a ENEVA.

Palavras- chave

Itaqui, valor justo, valuation, termelétricas, fluxo de caixa do acionista.

\section{Abstract}

Santos, Karine de Oliveira. Economic Financial Feasibility Analisys of a Termal Power Plant in Brazil: The Itaqui Case Study. Rio de Janeiro, 2016. 49 p. Final Work - Business Administration. Pontifícia Universidade Católica do Rio de Janeiro.

This study aims to make an economic-financial evaluation throught the valuation method by the discounted cash flow. This study will analyze a thermal power plant called Itaqui Geração de Energia S.A, located in northeast of Brazil.

This study addresses the main features of the development of a discounted cash flow, analyzing the historical active financial indices and conduct a brief analysis of how power plants operate in the Brazilian scenario.

This study aims to support economical management decisions related to Eneva company.

Key-words

Itaqui, thermal power plant, valuation, equity, free cash flow to equity. 


\section{Sumário}

10 tema e o problema de estudo 1

1.1. Introdução ao tema e ao problema do estudo 1

1.2. Objetivo do estudo 4

1.3. Objetivos intermediários do estudo 4

1.4. Delimitação e foco do estudo 5

1.5. Justificativa e relevância do estudo 5

2 Revisão de literatura $\quad 7$

2.1. O Setor de Energia Elétrica no Brasil

2.1.1. Geradoras de energia elétrica $\quad 7$

2.1.2. Termelétricas 10

3 Referencial Teórico 13

3.1. Avaliação pelo Método de Fluxo de Caixa Descontado 13

3.1.1. Fluxo de Caixa Livre aos Acionistas $\quad 14$

3.1.2. Cálculo do Custo de Capital Próprio (CAPM) 15

3.2. Análise de Índices Financeiros $\quad 18$

3.2.1. Indicadores de Liquidez $\quad 19$

3.2.2. Indicadores de Rentabilidade 20

3.2.3. Indicadores de Endividamento $\quad 21$

4 Métodos e procedimentos de coleta e de análise de dados do estudo 23

4.1. Método de pesquisa utilizado 23

4.2. Fontes de informações para coleta de dados no estudo 23

4.3. Procedimentos e instrumentos de coleta de dados utilizados 23

4.4. Formas de tratamento e análise dos dados coletados para o estudo

4.5. Limitações do Método 24 
5 Estudo de Caso 25

5.1. Itaqui 25

5.1.1. Premissas operacionais 26

5.1.1.1. Geração 26

5.1.1.2. Receitas fixa e variável 28

5.1.1.3. Custos Operacionais/ Despesas administrativas/ CAPEX 29

5.1.1.4. Dívida 29

5.1.2. Variação de Capital de Giro 30

5.1.3. CAPM 30

5.1.4. Resultados dos Índices Financeiros 31

5.2. Descrição dos resultados 32

5.2.1. Análise Cenário Realista 33

5.2.2. Análise de Cenário Pessimista 34

5.2.3. Análise de Cenário Otimista 35

5.2.4. Resultado dos Cenários 36

6 Conclusão e recomendação para novos estudos 38

$\begin{array}{ll}7 \text { Anexos } & 40\end{array}$

8 Bibliografia $\quad 47$ 


\section{Lista de figuras}

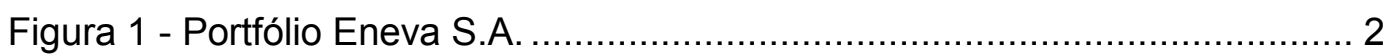

Figura 2 - Linha do tempo - Acontecimento ENEVA ........................................... 3

Figura 3 - Usina Termelétrica Itaqui ........................................................ 4

Figura 4 - Empreendimentos em operação ……......................................... 8

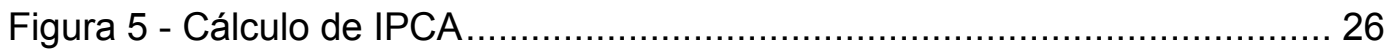

Figura 6 - Consumo de energia por subsistema ......................................... 27

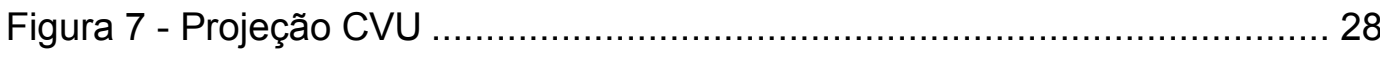

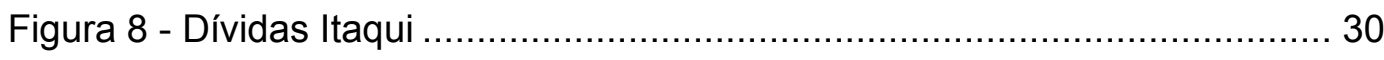

Figura 9 - Cálculo Variação de Capital de Giro............................................... 30

Figura 10 - Coeficiente beta Itaqui.......................................................... 31

Figura 11 - Resultados índices financeiros ................................................ 32

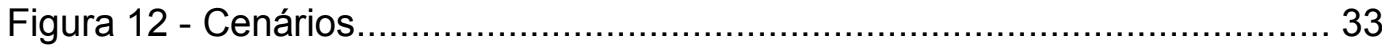

Figura 13 - DRE Cenário Realista ........................................................... 33

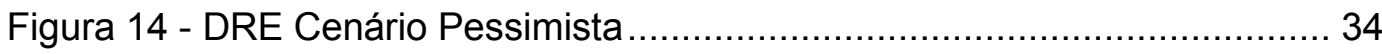

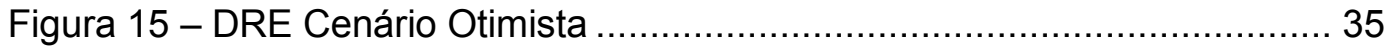

Figura 16 - Análise de Sensibilidade - Resultados...................................... 37 


\section{0 tema e o problema de estudo}

\subsection{Introdução ao tema e ao problema do estudo}

A avaliação de empresas é inerente a todo investidor que visa minimizar os riscos, sejam estes na venda ou na compra de um ativo, na realização de uma fusão, ao entrar na bolsa de valores, à entrada de novos sócios, entre outros fatores. A avaliação de ativos, mais conhecida como "valuation", procura identificar o preço justo das empresas. Quando o valor de uma empresa é estudado e analisado, é possível melhor avaliar os termos a serem negociados, e, com isso, o ativo está menos suscetível a uma possível subavaliação.

O presente trabalho tem como finalidade apresentar uma análise econômico-financeira de uma usina termelétrica. O modelo será construído a partir da usina de Itaqui, através de uma aplicação do método de fluxo de caixa descontado.

O método do fluxo de caixa descontado, frente aos inúmeros métodos conhecidos e disponíveis no mercado para avaliação do valor de empresas, é o mais recomendado pelos especialistas devido ao maior rigor técnico e conceitual. Esse tipo de avaliação, não só explica, mas também simula variáveis e premissas macroeconômicas, estratégicas, operacionais e financeiras que compõem todo o modelo de análise.

Para o presente estudo optou-se por analisar as termelétricas devido à grande importância de sua atuação na matriz energética brasileira. Segundo dados da ANEEL (2016), as termelétricas compõem a segunda parcela (29\%) mais significativa na matriz atual, contando com 2.831 usinas. Em primeiro lugar aparecem as usinas hidrelétricas que compõem outros $61 \%$ do sistema brasileiro.

A usina que será analisada nesse estudo é a Itaqui, localizada no Maranhão, com capacidade instalada de 360 MW. A Eneva, empresa controladora da usina Itaqui, possui em seu portfólio seis usinas termelétricas distribuídas pelo país. Segue abaixo o mapa do Brasil, no qual podem ser observadas as respectivas usinas controladas pela Eneva. 
Figura 1 - Portfólio Eneva S.A.

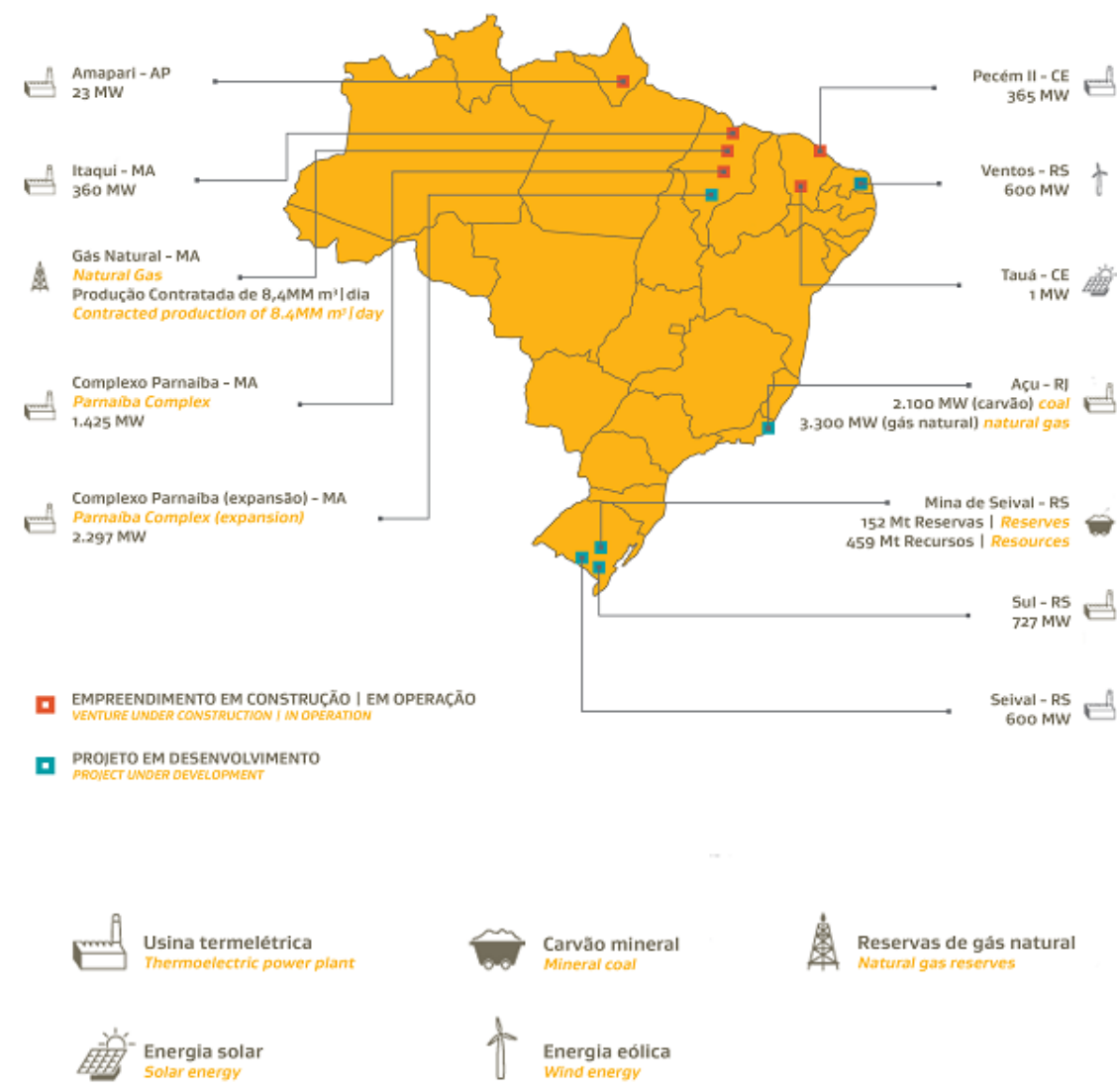

Fonte: RI Eneva.

A Eneva, em dezembro de 2014, recorreu à justiça entrando com pedido de Recuperação Judicial a fim de congelar por um tempo suas dívidas que já somavam bilhões de reais. É importante salientar que o pedido de recuperação judicial foi solicitado somente pela Eneva Holding, as usinas que compõem seu portfólio não tiveram suas dívidas congeladas.

Em meados de maio de 2015, a Eneva vendeu uma usina termelétrica chamada Porto do Pecém. Assim como Itaqui, movida a carvão, a usina foi vendida pelo montante de $\mathrm{R} \$ 300$ milhões. O valor de venda desse ativo não foi considerado justo por muitos consultores financeiros. A precificação do ativo não havia sido bem realizada, e por isso, ele foi subavaliado. A empresa de Consultoria Ernest \& Young avaliou o ativo em $\mathrm{R} \$ 1,6$ bilhão, enquanto a venda foi de $\mathrm{R} \$ 300$ milhões. 
Figura 2 - Linha do tempo - Acontecimento ENEVA

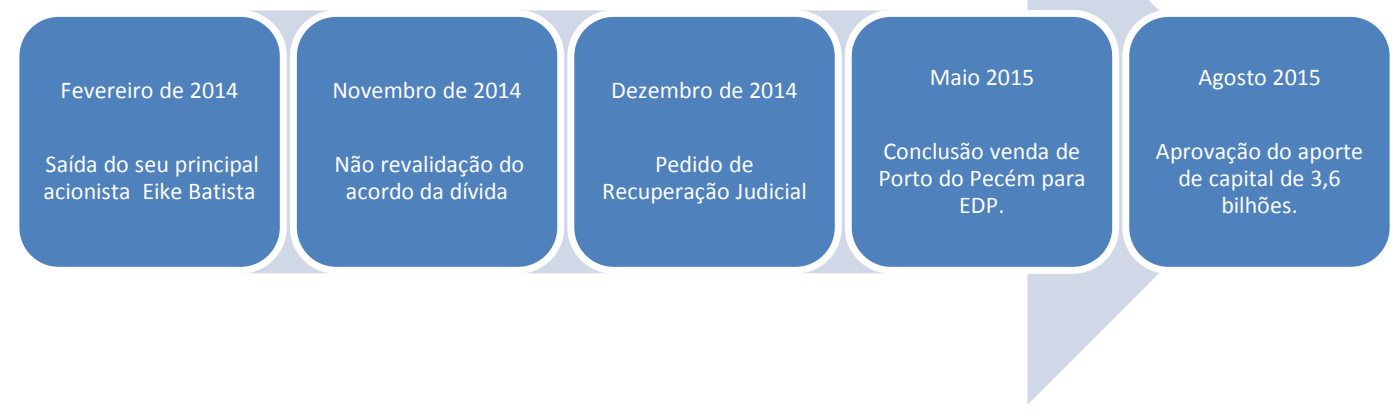

Fonte: RI ENEVA. Autoria própria.

Tendo em vista que a Eneva tem passado por crises financeiras após a forte queda do seu ex-acionista Eike Batista, conhecer o valor de seus investimentos é importante para que não ocorram subavaliações de ativos, como pode ser observado no caso da venda da usina de Porto do Pecém.

A procura por ativos que tragam um bom retorno para a empresa é um grande desafio em meio a incerteza do mercado atual. Mitigar o risco de possíveis perdas com subavaliações de ativos é a principal meta dos investidores, por isso, a avaliação de ativos é uma ferramenta importante para a tomada de decisões gerenciais.

A precificação do ativo nesse estudo será realizada através do modelo do Fluxo de Caixa Descontado. Para Assaf Neto (2013), o método de avaliação de empresas através do fluxo de caixa descontado é o que apresenta o maior rigor técnico e conceitual (...) estando perfeitamente consistente com o objetivo da empresa de maximização do seu valor de mercado.

Com o fluxo de caixa é possível identificar o valor presente da empresa com base nas projeções futuras que são realizadas na modelagem. Nesse modelo torna-se importante, não só o levantamento dos fluxos de caixa esperados, como também a maneira de sua distribuição ao decorrer do tempo.

O valor do ativo encontrado pelo fluxo de Caixa Descontado, considera o valor do dinheiro no tempo (Assaf Neto 2013). Isso significa que os valores esperados de retorno dos caixas futuros são trazidos a valor presente através da taxa de desconto denominada custo de capital. Foi escolhido nesse estudo o método de fluxo de caixa do acionista, pois tem-se a finalidade de encontrar o valor justo da empresa, considerando a visão do acionista, incluindo as dívidas da empresa que afetam o seu valor final. 
A Usina Termelétrica Itaqui, movida a carvão, começou sua operação em fevereiro de 2013, com capacidade instalada de 360 MW. Segundo o site de Relação com investidores da Eneva, a usina de Itaqui foi o primeiro investimento do grupo no Maranhão e gerou aproximadamente quatro mil empregos diretos, abrindo um leque de oportunidades numa região afastada da região populosa de São Luís. O empreendimento totaliza um investimento de R $\$ 2,2$ bilhões, sendo aplicada uma parcela de $30 \%$ em tecnologias que promovem o controle ambiental.

\section{Figura 3 - Usina Termelétrica Itaqui}

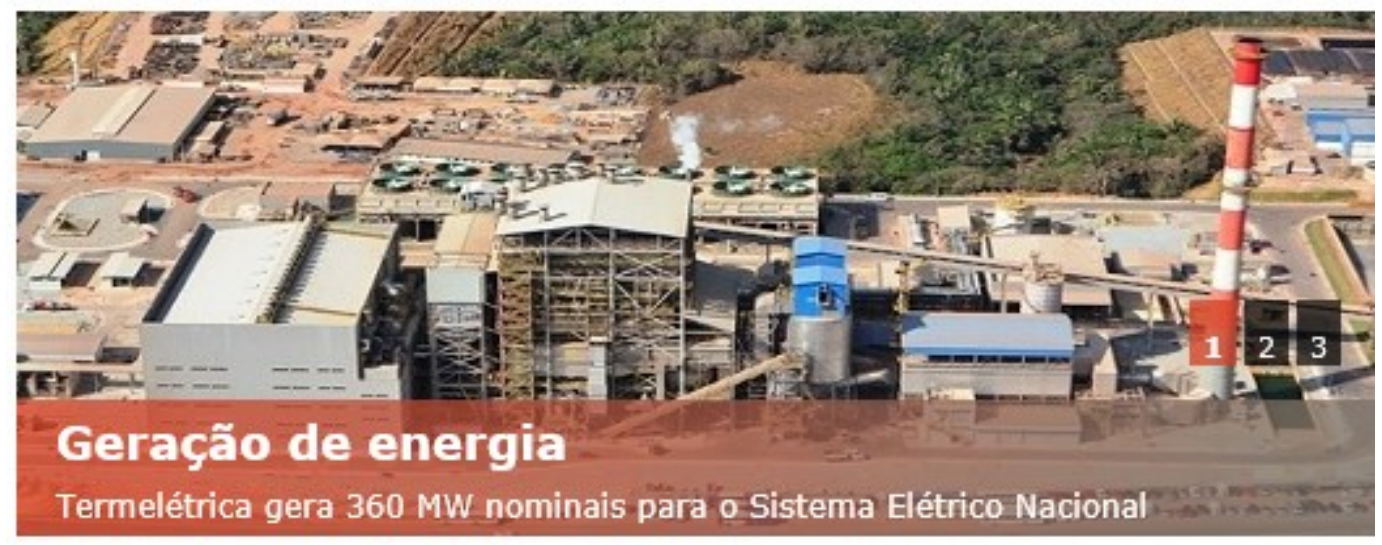

Fonte: ENEVA

Diante deste contexto, tem-se a seguinte questão problema: Qual é o valor justo da usina termelétrica Itaqui?

\subsection{Objetivo do estudo}

Avaliar o valor da usina termelétrica Itaqui Geração de Energia, a partir do método de Fluxo de Caixa Descontado, analisando suas demonstrações financeiras de 2013 a 2015 e projetando seus resultados até o fim do período de concessão de energia 2027. A fim de explicitar os fatores relevantes para uma análise econômico-financeira através do método de FCD e realizar uma breve análise de como atuam as geradoras de energia elétrica no Brasil.

\subsection{Objetivos intermediários do estudo}

Para que seja encontrado um valor justo mais próximo da realidade, a fim de minimizar os erros causados pela subjetividade na projeção das premissas, 
torna-se inerente ao estudo uma breve análise dos indicadores financeiros da usina de Itaqui nos anos de 2013 e 2015.

Analisar a atuação das geradoras termelétricas brasileiras e, em particular, a atuação da usina Itaqui, é importante para que sejam projetados os cenários de despacho e disponibilidade da usina.

A elaboração de cenários otimista, pessimista e realista foi necessária devido à instabilidade do setor de energia elétrica e do cenário econômico atual. Por isso, foram elaborados três cenários para identificar em qual desses a usina teria uma maior rentabilidade para o acionista.

\subsection{Delimitação e foco do estudo}

Propõe-se nesse trabalho a realização de um estudo de caso, a fim de avaliar o valor justo da usina termelétrica Itaqui Geração de Energia S.A. através do método do Fluxo de Caixa Descontado do Acionista. Os dados analisados são de 2013 ao final de 2015.

Os dados de 2013 a 2015 também foram utilizados para analisar os indicadores financeiros da usina de Itaqui. $\mathrm{O}$ ano de 2015 foi utilizado como base para projeção dos fluxos de caixa do acionista de 2016 até 2027, período de concessão de energia do leilão. Itaqui começou a operar em 2013, a partir do leilão A-5, no qual obteve 15 anos de concessão de energia no Ambiente de Contratação Regulada.

A área de abrangência do estudo é o território nacional, a atuação específica das geradoras de energia elétrica, e em particular, das termelétricas.

\subsection{Justificativa e relevância do estudo}

O cenário atual é de grande instabilidade econômica, por isso é importante para todo investidor avaliar de forma correta seus ativos. As subavaliações dos investimentos podem gerar grandes perdas para os investidores, por isso, o valuation é uma ferramenta importante para a tomada de decisões gerenciais, pois tem como objetivo reduzir esse risco de perdas nas transações. 
Não só para a Eneva, como para todas as empresas, é importante conhecer o valor de seu portfólio para que não ocorram subavaliações de ativos como pode ser observado no caso da Eneva, na venda da usina de Porto do Pecém.

Para fins acadêmicos, o estudo do valuation de uma empresa a partir do método de Fluxo de Caixa Descontado aplicado em uma empresa do segmento de energia poderá servir como base para os próximos estudos do mesmo segmento.

A realização desse estudo é relevante, uma vez que, é possível identificar que em nossa matriz, que as usinas termelétricas compõem a segunda maior parcela na geração de energia, representando aproximadamente $29 \%$ das usinas que estão em operação. 


\section{Revisão de literatura}

\subsubsection{Setor de Energia Elétrica no Brasil}

Atualmente, o setor elétrico brasileiro está subdivido em quatro grandes especificidades de negócios da cadeia produtiva, geração, transmissão, distribuição e comercialização de energia.

Nesse estudo serão abordadas as questões que envolvem as geradoras de energia elétrica, e em particular, as termelétricas.

\subsubsection{Geradoras de energia elétrica}

Segundo a ABRADEE ${ }^{1}$, a matriz energética brasileira é composta por inúmeras fontes de geração de energia, pelas linhas de transmissão e distribuição de energia, que juntas compõem a indústria de rede. A geração de energia é responsável por produzir a energia e colocá-la nos sistemas de transmissão e distribuição, a fim de que chegue ao consumidor final. Todo o sistema elétrico é conectado e exige um constante balanço de tudo o que é produzido e consumido. O Sistema Interligado Nacional (SIN) é composto em sua maior parte pelas hidrelétricas que possuem grandes reservatórios de regularização, que o tornam, em conjunto com a gama termelétrica instalada, um sistema no qual predominam fontes ditas como controláveis, ou seja, despachadas de forma centralizada pelo o Operador Nacional do Sistema Elétrico (ONS).

No gráfico abaixo, figura 4 , podem ser analisadas as parcelas atuais provenientes a cada tipo de geradora de energia existente em nossa matriz energética. É possível identificar que em nossa matriz, as usinas termelétricas compõem a segunda maior parcela na geração, representando aproximadamente $29 \%$ dentre os empreendimentos que estão em operação. As hidrelétricas de pequeno e grande porte compõem a principal fonte de energia no sistema, representando mais de $60 \%$ de toda geração de energia do país. Esse cenário pode ser justificado devido à vasta quantidade água em nosso

\footnotetext{
${ }^{1}$ ABRADEE - Associação Brasileira dos Distribuidores de Energia Elétrica.
} 
território, que é composto por uma das maiores reservas de água doce do mundo.

Além das hidrelétricas, existem outras fontes que podem ser consideradas, e que estão sendo muito demandadas na matriz brasileira, como a biomassa, gás natural, carvão, óleo combustível e nuclear, etc.

Figura 4 - Empreendimentos em operação

\section{Empreendimentos em operação - Geradoras}
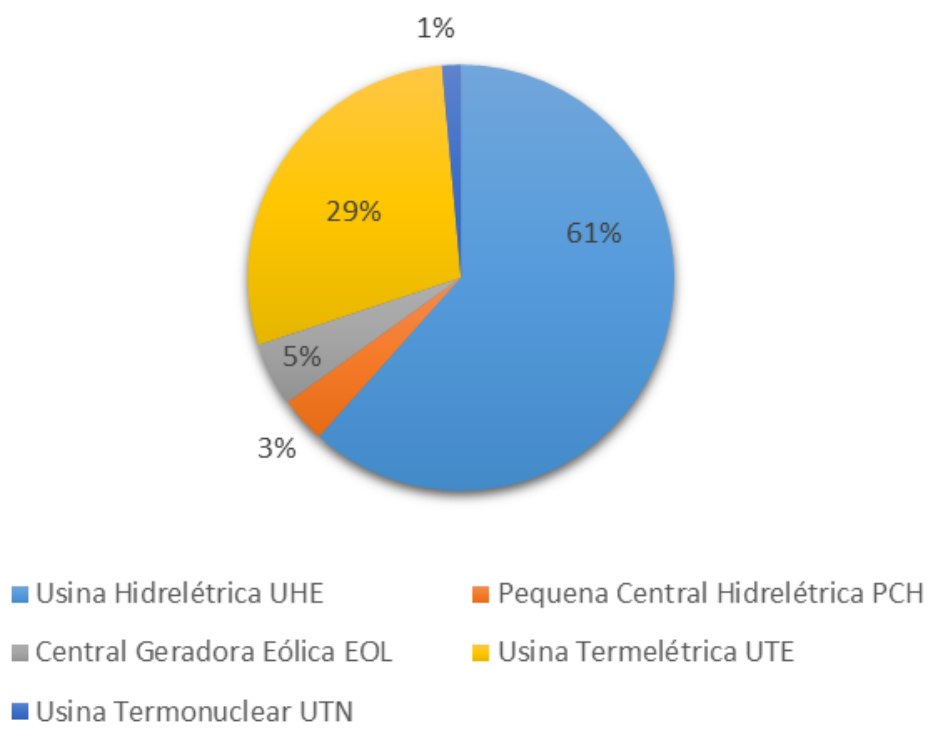

Fonte: ANEEL. Adaptado pelo autor.

O Plano Decenal de Expansão de Energia de 2024 elaborado pela EPE (Empresa de Pesquisa Energética) afirma que haverá uma significativa redução da participação das hidrelétricas em 2030. Já para as termelétricas a projeção é de que permaneçam com o mesmo nível de atuação. As eólicas terão um crescimento substancial devido aos últimos ganhos nos leilões de energia.

Segundo o MME (Ministério de Minas e Energia), o motivo de as termelétricas estarem sendo projetadas ao mesmo nível de 2015 se deve ao fato de essas usinas apresentarem características técnicas desejáveis ao Sistema Interligado de Energia (SIN), principalmente por não estarem sujeitas à vulnerabilidade climática, o que confere maior segurança energética ao país.

A agência reguladora do setor de energia elétrica, a ANEEL (Agência Nacional de Energia Elétrica), tem como principais objetivos a regulação da produção, transmissão, distribuição e comercialização da energia elétrica. 
A partir de 2004, passaram a existir dois ambientes de comercialização energia, Ambiente de Contratação Regulada e Ambiente de Contratação Livre. No Ambiente de Contratação Regulada (ACR), os agentes vendedores (geradores, comercializadores e autoprodutores) e as distribuidoras estabelecem Contratos de Comercialização de Energia no Ambiente Regulado (CCEAR) precedidos de licitação, ressalvados os casos previstos em lei, conforme regras e procedimentos de comercialização específicos (MINISTÉRIO DE MINAS E ENERGIA, 2016). Nesse ambiente, ocorrem leilões e licitações, a fim de que seja comercializada uma menor tarifa de energia.

A partir de 2005, os leilões introduziram uma competição entre os agentes de geração na contratação de energia elétrica, atendendo princípios de segurança no abastecimento e de modicidade tarifária, ou seja, a energia contratada a partir desse modelo resultou em aquisições pela menor tarifa, tendo como objetivo a redução do custo da energia elétrica. (MINISTÉRIO DE MINAS E ENERGIA, 2016).

No Ambiente de Contratação Livre (ACL), os geradores, consumidores livres, autoprodutores, comercializadores, importadores e exportadores de energia estabelecem entre si contratos bilaterais de compra e venda de energia com preços e quantidades livremente negociados, conforme regras e procedimentos de comercialização específicos. (MINISTÉRIO DE MINAS E ENERGIA, 2016). No $A C L$ são negociados os preços de forma livre para comercialização e geração de energia.

A Câmara de Comercialização de Energia Elétrica é o órgão responsável por viabilizar e gerenciar a comercialização de energia elétrica no Brasil. Tem como principais atribuições a realização das contabilizações de energia do que foi programado e do que está ocorrendo. Por exemplo, no momento em que uma distribuidora utiliza a demanda do sistema integrado ela não necessariamente conhece quem é o seu fornecedor naquele momento, todo o processo é realizado pela CCEE.

Em tempos de seca, aumenta a atuação da CCEE, uma vez que as termelétricas estão trabalhando mais no sistema, e essas usinas geram energia mais cara que as hidrelétricas. Desse modo, a CCEE faz a contabilidade dessas operações de compra e venda de energia, constatando todo mês as diferenças entre os valores que haviam sido contratados e os montantes que foram de fato gerados ou consumidos pelos agentes de mercado. A CCEE realiza a liquidação financeira das diferenças, calculando o Preço de Liquidação das Diferenças (PLD). No âmbito do mercado regulado (ACR), a CCEE tem como atribuição 
realizar os leilões de compra e venda de energia, assim como gerenciar os contratos firmados nesses leilões.

A Câmara de Comercialização de Energia (CCEE) realiza periodicamente leilões de compra de energia elétrica. Os leilões possuem uma parcela importante dos contratos de energia do Ambiente de Contratação Regulada (ACR), tratam-se de processos licitatórios nos quais os compradores e vendedores formalizam os seus interesses pela energia fornecida a fim de atender plenamente a demanda futura. Os contratos são formalizados no mercado regulado (ACR) e são chamados de Contratos de Comercialização de Energia Elétrica em Ambiente Regulado (CCEAR).

Segundo a Empresa de Pesquisa Energética (EPE, 2016), órgão responsável pelo planejamento do setor elétrico a longo prazo, o sistema elétrico brasileiro possui um tipo de complexidade natural que demanda investimentos constantes, a fim de que eles auxiliem o ONS nas tomadas de decisões quanto à operação energética.

\subsubsection{Termelétricas}

Segundo dados da ANEEL (2016), as termelétricas compõem a segunda parcela $(29 \%)$ mais significativa na matriz energética brasileira, contando com 2.831 usinas. Entretanto, esse valor é significativamente menor que as usinas hidrelétricas do Governo que compõem outros $61 \%$. Há ainda outras formas alternativas de energia que estão em pleno crescimento como as usinas de energias renováveis.

$\mathrm{Na}$ geração de energia pode-se dividir as fontes de energia em dois tipos, convencionais e alternativas. As fontes convencionais são basicamente as usinas hidrelétricas que possuem grande porte, ou seja, as que possuem uma potência superior a $30 \mathrm{MW}$. Além dessas, são tidas como convencionais as termelétricas movidas a carvão, gás natural, diesel, as nucleares, etc. Já para as fontes alternativas são incluídas as usinas que utilizam a queima da biomassa, as usinas solares, eólicas e centrais hidrelétricas (pequeno porte).

Lima e Souza (2014) afirmam que uma usina termelétrica é uma planta química que produz energia a partir do calor gerado pela queima de combustíveis fósseis, ou por outras fontes de calor, como, por exemplo, a fissura nuclear.

A Associação Brasileira de Geradoras Termelétricas (ABRAGET), constituída em 2001, segundo seu site institucional, tem como finalidade 
principal a defesa dos direitos, interesses e aspirações das associadas através da representação perante os poderes públicos e quaisquer outros órgãos e instituições. Vieira (2015), afirma que o país é plenamente dependente das termelétricas. Ele salienta que essas usinas foram desenvolvidas a priori com a finalidade somente de "proteger" o sistema, isto é, as UTE's precisariam ser chamadas a despachar somente quando as usinas do Governo não suprissem totalmente a necessidade dos fornecedores.

A Empresa de Pesquisa Energética (EPE), em seu Plano Decenal 2024, afirma que em virtude da baixa qualidade do carvão nacional, que apresenta alto teor de inertes e enxofre, é essencial que as novas termelétricas utilizem novas tecnologias focadas em reduzir a emissão de poluentes atmosféricos.

Por isso, e por serem caras, essas usinas foram construídas para serem acionadas quando realmente houvesse necessidade. Atualmente, pode-se observar que as termelétricas são inerentes ao sistema permanecendo ligadas full time ${ }^{3}$. De acordo com o Plano Decenal 2024, as termelétricas geraram aproximadamente $5 \%$ de todo consumo elétrico nacional em 2011, passando para 16\% em 2013 e 30\% em 2014. Antes consideradas apenas como uma fonte alternativa, para suportar eventuais quedas do sistema, hoje, são tidas como fontes essenciais para o seu pleno funcionamento.

A operação das usinas é controlada pelo Operador Nacional do Sistema Elétrico (ONS), que tem como responsabilidade atender à demanda sempre ao preço mais baixo. Sabe-se que o menor custo é das hidrelétricas, visto que produzem a base de água, e que as termelétricas teriam que ser acionadas apenas nos períodos em que há escassez de chuvas, pois os reservatórios das hidrelétricas estão abaixo dos níveis de captação.

Para Salvador (2011), o sistema brasileiro de geração de energia elétrica possui uma peculiaridade: as usinas termelétricas dão mais lucro quando ficam paradas do que quando estão sendo chamadas a despachar.

Esse fato ocorre, pois o ONS estabelece dois tipos de pagamentos para as usinas termelétricas em seu contrato. As UTE's possuem receita quando estão sendo acionadas, e também quando não são chamadas a despachar, ou seja, sem estarem operando elas recebem uma receita fixa estabelecida no leilão. Quando geram energia elas são remuneradas a preço de seu custo variável (CVU).

\footnotetext{
${ }^{2}$ Usinas Termelétricas

${ }^{3}$ Full time - Significa que as termelétricas estão acionadas por todo o tempo. Sendo despachadas durante todo o tempo pelo ONS.
} 
Salvador (2011) explica que a remuneração de quando a usina é chamada a despachar é o valor cobrado por ela para cobrir suas despesas operacionais e com combustível que elas possuem ao gerar energia. E a segunda forma de remuneração é uma "taxa de aluguel", a receita fixa da usina é remuneração apenas por estar disponível quando o ONS precisar de seus serviços. 


\section{Referencial Teórico}

\subsection{Avaliação pelo Método de Fluxo de Caixa Descontado}

Para Assaf Neto (2013) a definição do valor de mercado de uma empresa é uma missão um tanto quanto complexa, demandando uma coerência e uma análise criteriosa na formulação do modelo de avaliação. O autor ainda afirma que não há como prescindir de certa subjetividade na definição desse valor, principalmente por se tratar de um trabalho baseado em resultados esperados a partir de forças que atuam no mercado.

A avaliação de ativos tem como objetivo encontrar o valor justo da empresa, esse valor servirá como base para tomada de decisão de possíveis fusões, aquisições ou liquidações de ativos (Assaf Neto, 2013).

Saurin, Lopes e Junior (2009) afirmam que a grande dificuldade para a avaliação de empresas é que o valor resulta de fatores que estão no futuro, portanto, o que vai acontecer no futuro é inserido nos modelos de acordo com as premissas do analista, podendo conter informações analisadas de forma errônea ou subjetiva.

Sabendo que os dados futuros são tidos como incertos e imprevisíveis, e como as premissas são variáveis, não se pode nunca esperar que um método obtenha o real valor de uma empresa (Saurin, Lopes e Junior 2009), com isso, o valor obtido é composto por estimativas razoáveis do valor justo de uma empresa. O valor que será encontrado através da análise, será uma estimativa do quanto pode custar a empresa de acordo com as premissas utilizadas.

Assaf Neto (2013) salienta que frente a inúmeros métodos conhecidos e disponíveis no mercado para avaliação do valor de empresas, o método do Fluxo de Caixa Descontado é reconhecido pelo mercado pelo seu maior rigor técnico e conceitual. Porque esse método que não só explica, como também simula variáveis e premissas macroeconômicas, estratégicas, operacionais e financeiras que compõem todo o método de análise.

A metodologia do FCD também identifica para o investidor suas preferências em relação ao risco e a taxa de remuneração mais condizente a remunerar os acionistas (Assaf Neto, 2013). 
Sabe-se que o método FCD utiliza como base os fluxos de caixa gerados pelo ativo, projetando-os até a perpetuidade, por isso, pode-se afirmar que essa metodologia informa o valor de um negócio tendo em vista os benefícios futuros que ele produzirá. Como a definição do valor da empresa utiliza-se do valor do dinheiro no tempo, os valores futuros são trazidos a valor presente através da utilização da taxa de desconto, conhecida como custo de capital.

Para Damodaran (2001) existem duas aberturas para a realização do Valuation de uma empresa pelo método do fluxo de caixa descontado. O primeiro consiste na avaliação da participação do acionista no negócio (Fluxo de Caixa Livre ao Acionista) e o outro implica em avaliar a empresa como um todo (Fluxo de Caixa Livre à Empresa). O autor ainda afirma que apesar de ambas as abordagens descontarem os fluxos de caixa esperados, os fluxos de caixa e as taxas de desconto são diferentes em cada caminho.

\subsubsection{Fluxo de Caixa Livre aos Acionistas}

Para Damodaran (2001), o Fluxo de Caixa do Acionista consiste no fluxo de caixa existente após o pagamento de despesas operacionais, juros e principal, e de qualquer desembolso de capital necessário à manutenção da taxa de crescimentos dos fluxos projetados.

Sendo assim, pode-se afirmar que o Fluxo do Acionista é o valor residual após o atendimento de todas as necessidades financeiras da empresa. Caso ele seja negativo, a empresa precisará obter um capital para suprir essas necessidades. Se for um fluxo de caixa positivo, a empresa poderá repassar aos outros acionistas em forma de dividendos.

A composição do Fluxo de Caixa Livre aos Acionistas é descrita a seguir:

\section{Receitas}

(-) Despesas Operacionais

(-) Depreciação

(=) Lucro antes do pagamento de juros e impostos (EBIT)

(-) Despesas com juros

(=)Lucro antes dos impostos 
(-) Impostos

(=) Lucro líquido

(+) Depreciação e Amortização

(-) CAPEX

(-) Variação do Capital de Giro

(-) Pagamento de Principal de Dívidas

$(+)$ Novas Captações

(=) Fluxo de Caixa do Acionista (FCA) ou Free Cashflow to Equity (FCFE)

O método FCA ou FCFE analisa o valor da empresa sob a perspectiva do acionista, calculando o valor de sua "riqueza" do acionista, avaliando o capital próprio. O cálculo é realizado da seguinte forma:

Valor do Patrimônio Líquido $=\sum_{t=1}^{t=\infty} \frac{F C F E_{t}}{(1+K e)^{t}}$

Onde:

$\mathrm{Ke}=$ Custo do Capital próprio

$\mathrm{t}=$ Vida útil do ativo

FCFEt $=$ Fluxo de Caixa para o Acionista no tempo $t$

O valor do acionista é o valor presente do fluxo de caixa destinado ao acionista. O custo de patrimônio líquido é a taxa de retorno exigida pelos investidores para realizarem um investimento em uma empresa.

\subsubsection{Cálculo do Custo de Capital Próprio (CAPM)}

O CAPM (Capital Asset Pricing Model), modelo de precificação de ativos, é o método utilizado para calcular a taxa mínima de retorno esperada que um investimento precisa oferecer para ser atraente ao acionista. O retorno mínimo esperado é denominado custo de capital do investimento. 
Ross, Westerfield e Jordan (2011), explicam que o custo de capital é denominado dessa forma porque o retorno exigido é o que a empresa precisa gerar sobre seu capital investido num projeto, podendo ser interpretado como custo de oportunidade associado ao investimento de capital pela empresa.

Para Assaf Neto (2007) o princípio fundamental de toda empresa é oferecer um retorno dos seus investimentos que cubra a expectativa mínima de ganho de seus proprietários de capital.

O modelo CAPM estabelece uma relação linear de risco e retorno, viabilizando dessa forma encontrar para cada nível de risco assumido, o valor de retorno que receberia como prêmio por essa situação.

Segundo Ross, Westerfield e Jordan (2011), o risco sistemático é fator determinante crucial do retorno esperado do ativo. O coeficiente Beta $(\beta)$ explica o quanto de risco sistemático determinado ativo tem em relação a um ativo médio. Ross, Westerfield e Jordan (2011), explicam que como o risco não sistemático pode ser reduzido sem custo mediante a diversificação da carteira, o princípio do risco sistemático diz que a recompensa por assumir o risco depende apenas do nível de risco sistemático.

Segue abaixo a fórmula do retorno esperado do ativo:

Retorno exigido do ativo $=R_{f}+\beta\left(R_{m}-R_{f}\right)$

Onde:

$\mathrm{Rf}=$ taxa livre de risco (valor puro do dinheiro no tempo)

$\beta=$ risco sistemático

$\mathrm{Rm}=$ risco de mercado

$(\mathrm{Rm}+\mathrm{Rf})=$ prêmio pelo risco de mercado

Segundo Ross, Westerfield e Jordan (2011), a taxa livre de risco (Rf), mostra a recompensa exigida por simplesmente esperar pela devolução do dinheiro, sem assumir risco nenhum. Esse percentual é calculado através de uma média das taxas históricas de juros dos títulos públicos.

Entretanto, segundo Assaf Neto (2007), no Brasil não é aconselhável realizar esse procedimento por entender-se que os títulos emitidos pelo governo deveriam embutir um valor para o prêmio de risco. Por isso, esses títulos não são aceitos como ativos livres de risco pelo mercado financeiro, por não 
incluírem um valor para o prêmio de risco e por possuírem séries históricas com muita dispersão ao longo dos anos.

Devido à tais dificuldades, para os países emergentes, o cálculo do Custo de Capital próprio não é uma tarefa simples. A fim de realizar o cálculo do custo do capital próprio, a mensuração dos valores das taxas foi realizada utilizando como bechmark ${ }^{4}$ os valores de títulos emitidos pelo Tesouro do Governo dos Estados Unidos, que possuem zero de risco.

Ainda com a finalidade de ajustar o valor do CAPM no Brasil e estimar o capital próprio, torna-se necessário a inclusão do Risco Brasil, sendo somado o valor do risco de default ${ }^{5}$ ao final da equação. Esse risco mede o grau de perigo que um país de economia emergente oferece ao investidor estrangeiro.

Dessa forma, devido à grande volatilidade das taxas brasileiras, o cálculo do Custo de Capital próprio das empresas brasileiras, é melhor realizado quando são utilizadas as taxas americanas somadas ao risco país.

$$
\begin{aligned}
& \text { Retorno exigido do ativo }=R_{f}+\beta\left(R_{m}-R_{f}\right)+R_{p} \\
& \text { Onde: } \\
& \mathrm{Rf}=\text { Ativo livre de Risco (risk free rate) } \\
& \beta=\text { Risco sistemático } \\
& \mathrm{Rm}=\text { Retorno do mercado de ações } \\
& \mathrm{Rp}=\text { Risco país }
\end{aligned}
$$

O cálculo do risco sistemático de empresas alavancadas requer um melhor tratamento do coeficiente beta. Isto é, para que seja calculado o efeito da dívida no risco do negócio, torna-se necessário desalavancar o beta de acordo com o percentual de dívida sobre o patrimônio líquido das empresas do setor de energia americano. A fórmula abaixo explica como é realizada a desalavancagem do coeficiente beta.

$$
\beta_{U}=\frac{\beta_{L}}{\left[1+\left(\frac{D}{E}\right) x(1-I R)\right]}
$$

Onde:

$\mathrm{Bu}=$ Beta desalavancado

\footnotetext{
${ }^{4}$ Benchmark é um termo em inglês que tem significa obter um ponto de referência, um parâmetro, uma medida que sirva de comparação.

${ }^{5}$ Risco de default é o risco de o país quebrar e não pagar suas dívidas.
} 
$\mathrm{BI}=$ Beta alavancado

$\mathrm{D}=$ Dívida

$E$ = Patrimônio Liquido

IR = Imposto de Renda

Para que seja refletido o efeito da própria dívida do negócio, é necessário realavancar o Beta de acordo com as dívidas existentes da empresa em questão.

$\beta_{L}=\beta_{U} x\left[1+\left(\frac{D}{E}\right) x(1-I R)\right]$

Onde:

$\mathrm{Bu}=$ Beta desalavancado

$\mathrm{BI}=$ Beta alavancado

D = Dívida

$E$ = Patrimônio Liquido

IR = Imposto de Renda

Acredita-se que outras formas mais complexas conseguiriam explicar o retorno do acionista de maneira mais real, no entanto, Povoa (2012) explica que a relação de custo/benefício de adotar algo mais complexo é desfavorável, tendo em vista que é necessário levar em consideração que as regressões se baseiam em fatos passados, podendo assim, distorcer qualquer projeção futura.

Para Endler (2004) o cálculo de obtenção do custo de capital próprio é um dos pontos mais difíceis do processo de avaliação de empresas, uma vez que o capital precisa ser estimado por meio do processo, o que envolve um alto grau de subjetividade e possível erro.

\subsection{Análise de Índices Financeiros}

Para realizar uma análise econômico-financeira completa da usina de Itaqui, a fim de que sejam minimizados os possíveis erros de subjetividade ao realizar a projeção das premissas, torna-se importante ter conhecimento de seus dados passados, analisando seus principais indicadores de desempenho econômico.

Para Fernandes (2004), a análise de indicadores financeiros por si só não é suficiente para obter um bom conhecimento do desempenho da empresa. Por 
isso, a elaboração dos indicadores financeiros de Itaqui nesse presente estudo será um complemento para que seja estimado um valor justo mais próximo da realidade. $\mathrm{O}$ autor salienta que a ênfase demasiada na análise dos indicadores financeiros pode causar problemas futuros à empresa, pois eles não consideram os cuidados que devemos ter em relação ao ambiente externo.

Os indicadores financeiros têm a tarefa de medir uma atividade, explicando dessa forma as fases de um processo (Fernandes, 2004).

O objetivo ao analisar os indicadores financeiros de Itaqui é o de entender quais eram as fases desse projeto em 2013 e 2015. Para isso, serão analisados os seguintes indicadores:

\subsubsection{Indicadores de Liquidez}

Para Kuhn e Lampert (2012) os índices de liquidez evidenciam a base da situação da empresa, isto é, constituem uma apreciação sobre sua capacidade de cumprir com os compromissos a partir da comparação entre os direitos disponíveis e realizáveis com as obrigações da empresa.

O índice de liquidez corrente aponta o total que a empresa possui em caixa mais bens e direitos realizáveis a curto prazo em comparação as suas dívidas no mesmo prazo. Kuhn e Lampert (2012) afirmam que a liquidez corrente é o índice mais utilizado pelos analistas financeiros.

Liquidez Corrente: $\quad \frac{A C}{P C}$

Onde:

AC - Ativo Circulante

PC - Passivo Circulante

Liquidez corrente é a capacidade de honrar as obrigações a curto prazo em dia. Quanto maior o valor do índice, melhor a capacidade de saldar as obrigações a curto prazo. Esse índice é favorável quando superior a 1. Enquanto os índices menores que 1 , demonstram a insuficiência de fundos para liquidar as obrigações a curto prazo. 
O cálculo da liquidez seca aponta o quanto a empresa possui de disponibilidade, sendo o mesmo cálculo que a liquidez corrente, porém sem os estoques. Eliminando, dessa forma, a incerteza da venda de estoques.

Liquidez Seca: $\quad \frac{A C-E}{P C}$

Onde:

AC - Ativo Circulante

$E-$ Estoques

PC - Passivo Circulante

A liquidez geral tem como objetivo mostrar a saúde financeira de longo prazo da empresa. Para Oliveira (2013), a liquidez geral representa o quanto a empresa possui de ativo circulante e realizável ao longo prazo para cada $\mathrm{R} \$$ 1,00 de dívidas total. Resultados superiores a $R \$ 1,00$ expressa que a empresa tem bens e direitos suficientes para honrar seus compromissos financeiros.

Liquidez Geral: $\quad \frac{A C+\text { Realizável à longo prazo }}{P C+\text { Exigível à longo prazo }}$

Onde:

AC - Ativo Circulante

PC - Passivo Circulante

Para Kuhn e Lampert (2012) não é possível analisar os índices de liquidez como medida isolada, indicando se a empresa é boa ou ruim, pois essa análise depende do tipo de atividade da empresa, e, especialmente, de seu ciclo financeiro.

\subsubsection{Indicadores de Rentabilidade}

Os indicadores de rentabilidade informam a remuneração a ser recebida de acordo com os recursos investidos na empresa durante certo período.

Segundo Matarazzo (2003), os índices de rentabilidade informam qual a rentabilidade de todos os capitais que foram investidos na empresa, isto é, quanto renderam os investimentos e, portanto, qual o grau de êxito econômico da empresa. 
Para Albrecht (2011), a margem EBITDA é considerada como um índice que aproxima o fluxo de caixa da empresa em cada $R \$ 1,00$ de receita antes das despesas financeiras, impostos, depreciações e amortizações.

$$
\text { Margem EBITDA: } \frac{\text { EBITDA }}{\text { Receita Líquida }}
$$

Esse índice é tido como um indicador da margem de lucro operacional da empresa. Essa margem demonstra o quanto a empresa possui de superávit ou déficit. As empresas que possuem uma dívida alta podem possuir uma margem operacional boa, mas um resultado final ruim.

Para Kuhn e Lampert (2012) o índice de retorno sobre o patrimônio líquido, mais conhecido como ROE, indica quanto de prêmio os acionistas ou proprietários da empresa estão obtendo em relação aos seus investimentos de capital próprio no empreendimento.

Esse índice tem como objetivo mensurar o quanto a empresa obteve de lucro para cada valor de capital investido.

$$
\text { ROE: } \frac{\text { Lucro Líquido }}{\text { Patrimonio Líquido }}
$$

\subsubsection{Indicadores de Endividamento}

Para Rodrigues (2012) os índices de endividamento demonstram o quanto a empresa deve para bancos e demais instituições financeiras dentro de seu quadro geral de endividamentos (passivo). Eles revelam o grau de endividamento da empresa e ajudam a entender como a empresa tem financiado seu ativo, com recursos próprios ou de terceiros.

O Endividamento Geral tem como objetivo analisar o percentual do passivo da empresa composto por dívidas a curto e longo prazo.

Endividamento Geral: $\frac{P C+P N C}{P T} \times 100$

Onde:

$\mathrm{PC}=$ Passivo Circulante

$\mathrm{PNC}=$ Passivo não circulante 


\section{$\mathrm{PT}=$ Passivo Total}

Sendo assim, esse índice indica que quanto maior o nível de Endividamento Geral da empresa, maiores serão os riscos de uma execução da dívida e maiores serão as possibilidades de gastos com despesas financeiras que, por sua vez, reduzirão a eficiência geral da empresa. (Rodrigues, 2012) 


\section{Métodos e procedimentos de coleta e de análise de dados do estudo}

\subsection{Método de pesquisa utilizado}

Tendo em vista que a finalidade do estudo é a de encontrar o valor justo para a usina Itaqui, a metodologia utilizada nesse trabalho para avaliar o valor justo da empresa em questão é o Fluxo de Caixa Descontado, método o qual foi descrito no item 3, Referencial Teórico.

\subsection{Fontes de informações para coleta de dados no estudo}

Tratando-se de um estudo de caso, foram realizadas pesquisas bibliográficas e documentais. As informações analisadas foram coletadas no site institucional da empresa ENEVA S.A., tendo em vista que se trata de uma Sociedade Anônima.

Serão utilizados Balanços Patrimoniais e Demonstrações de Resultados da empresa Itaqui Geração de Energia S.A. do ano de 2013 a 2015.

\subsection{Procedimentos e instrumentos de coleta de dados utilizados}

Para Gil (2010) o estudo em questão pode ser classificado como uma pesquisa bibliográfica por utilizar "fontes de papel" e exploratória por envolver um Estudo de Caso.

Do ponto de vista dos procedimentos técnicos Gil (2010) afirma que quando a pesquisa é elaborada a partir de material já publicado, constituído principalmente de livros, artigos e materiais já disponibilizados na internet, a pesquisa pode ser definida como bibliográfica.

\subsection{Formas de tratamento e análise dos dados coletados para o estudo}

As análises obtidas através de Balanços Patrimoniais e Demonstrações Contábeis da empresa Itaqui Geração de Energia S.A., serão retiradas do site de 
Relações Institucionais da empresa. As informações serão utilizadas para a composição do Fluxo de Caixa Descontado.

\subsection{Limitações do Método}

De acordo com Assaf Neto (2007), o método Valuation pode apresentar três fontes de incerteza:

"Primeiro, as incertezas nas estimativas (mesmo com fontes de informações impecáveis, a própria manipulação dos dados, torna a avaliação sujeita a erros de estimativa); em segundo, as incertezas específicas da empresa (quando o caminho vislumbrado para a empresa pode se tornar muito diferente, acreditando-se que uma empresa pode acabar tendo um desempenho melhor do que os lucros e fluxos de caixa esperados); e, por fim, as incertezas econômicas, as quais toda empresa está sujeita ao ambiente macroeconômico."

A avaliação está limitada aos dados disponibilizados pela empresa e pelo mercado, tendo como base somente a visão externa à empresa, isto é, sem informações privilegiadas.

Segundo Ross, Westerfield e Jordan (2011), o cálculo de índices financeiros possui limitações quanto a teoria, pois não há uma teoria que consiga ajudar o analista a identificar qual item ou indicador deve ser examinado e servir como guia no estabelecimento de padrões.

Nesse trabalho houve uma limitação de estudo quanto à projeção do PLD (Preço de Liquidação das Diferenças). Optou-se por não projetar o PLD por causa da grande probabilidade de erro quando projetado por um longo período devido às suas grandes variações. Esse erro poderia prejudicar as análises do fluxo de caixa descontado. Outro motivo de não projetar o PLD é devido a pequena porção da energia que é destinada ao mercado livre $(A C L)$, somente $7 \%$, enquanto para o mercado regulado (ACR) é de $93 \%$. Sendo assim, um valor muito pequeno se comparado ao mercado regulado. 


\section{Estudo de Caso}

\subsection{Itaqui}

A usina termelétrica situada no Maranhão, nordeste do Brasil, gera energia a partir da queima do carvão mineral e, por esse motivo, antes de entrar em operação sofreu alguns impedimentos devido ao impacto ambiental que causaria quando fosse construída.

Sabe-se que o carvão, é um combustível fóssil, altamente poluente, e que, traz danos ao ambiente. O maior impacto ambiental produzido pelas termoelétricas são os gases lançados a atmosfera que contribuem amplamente para o crescimento do efeito estufa. São produzidos óxidos e dióxidos de enxofre, óxidos de nitrogênio, monóxido e dióxido de carbono, alguns outros gases e também particulados.

Além de efeitos sobre o quadro natural, a implantação da usina ocasionou impactos sociais particularmente negativos, afetando a acessibilidade e desarticulando a subsistência de moradores locais tradicionalmente estabelecidos nas cercanias do terreno da usina. De acordo com Carvalho \& Cidade (2014), parte da população de São Luís aceitou propostas de deslocamento e realocação para áreas distantes. Outra parte, organizada, passou a agir: para manifestar-se e ser reconhecida, buscando comparecer às audiências públicas; na tentativa de recorrer a seus direitos de ocupação e acesso às terras, acionou o Ministério Público; com o apoio da mídia, realizou protestos.

Devido a esse e outros impactos ambientais nos quais as instituições públicas responsáveis apontavam irregularidades na construção do empreendimento por causa de descumprimentos e deficiências no licenciamento apresentados ao IBAMA $^{6}$, a usina teve sua operação adiada por aproximadamente 100 dias.

Quando enfim, a usina de Itaqui teve o início de sua operação aprovada pela ANEEL, a termelétrica começou a gerar energia com $360 \mathrm{MW}$ de capacidade instalada. O leilão A-5 que ocorreu em 2007, aprovou a comercialização de $315 \mathrm{MW}$ médios, durante o período de 15 anos.

\footnotetext{
${ }^{6}$ Instituto Brasileiro do Meio Ambiente e dos Recursos Naturais Renováveis.
} 
O contrato propôs uma receita anual inicial de $\mathrm{R} \$ 299,8$ milhões, tomando como base Outubro de 2012, ajustada anualmente pelo IPCA em novembro. Em Abril de 2016, a empresa Eneva reportou em seu Release trimestral, uma receita fixa de Itaqui de aproximadamente $\mathrm{R} \$ 89,8$ milhões no último trimestre de 2015 , projetando esse valor até o final de dezembro, teríamos o valor total de $\mathrm{R} \$ 359$ milhões de receita fixa.

Adicionalmente, a usina possui uma receita variável que cobre os custos variáveis, ou seja, os custos que estão relacionados à geração, quando a termelétrica for solicitada despachar pelo Operador Nacional do Sistema (ONS).

Os valores de IPCA registrados na tabela a seguir, utilizados para reajustar a Receita Fixa anualmente, foram extraídos dos Relatórios de Mercado Semanais do Focus, calculados pelo Banco Central do Brasil.

Figura 5 - Cálculo de IPCA

\begin{tabular}{|c|c|c|c|c|c|c|}
\hline IPCA & 2015 & 2016E & 2017E & 2018E & 2019E & $2020 \mathrm{E}$ \\
\hline Focus (Banco Central) & $9,29 \%^{1}$ & $7,26 \%^{2}$ & $5,66 \%^{2}$ & $6,46 \%^{3}$ & $6,46 \%$ & $6,46 \%$ \\
\hline
\end{tabular}

Fonte: Focus - Relatório de Mercado - Adaptado pelo autor

\subsubsection{Premissas operacionais}

\subsubsection{Geração}

No ano de 2015, de acordo com os resultados divulgados pela Eneva, a geração de Itaqui foi de $3.456 \mathrm{GWh}$. A disponibilidade foi de $100 \%$, isto é, esteve todo tempo disponível para o ONS. O percentual de despacho médio no ano foi de aproximadamente $80 \%$. Esse alto nível de despacho foi devido à escassez de chuvas na região nordeste.

A projeção de despacho, e, consequentemente, a geração da usina para os próximos anos será realizada com base no Relatório Decenal de Expansão de 2015 com projeção a 2024 da Empresa de Pesquisa Energética.

A partir da figura 6, do Plano Decenal de Expansão Energética, pode-se observar que a demanda por energia no subsistema nordeste, no qual Itaqui comercializa energia, irá aumentar em $53 \%$ até 2024 . O setor siderúrgico é o que mais demanda a energia gerada pelo carvão mineral, significando $94 \%$ da 
demanda total. Com isso, o Plano Decenal associa a expansão do setor siderúrgico ao crescimento da demanda de energia.

Figura 6 - Consumo de energia por subsistema

\begin{tabular}{|c|c|c|c|c|c|c|c|}
\hline \multirow[b]{2}{*}{ Ano } & \multicolumn{4}{|c|}{ Subsistema } & \multirow{2}{*}{ SIN } & \multirow{2}{*}{$\begin{array}{l}\text { Sistemas } \\
\text { Isolados }\end{array}$} & \multirow{2}{*}{ Brasil } \\
\hline & Norte & Nordeste & Sudeste/CO & Sul & & & \\
\hline & \multicolumn{7}{|c|}{ GWh } \\
\hline 2015 & 34.177 & 72.617 & 276.678 & 85.070 & 468.542 & 2.377 & 470.918 \\
\hline 2019 & 41.625 & B4.839 & 312.820 & 95.992 & 535.276 & 2.117 & 537.393 \\
\hline 2024 & 58.598 & 110.954 & 399.410 & 119.706 & 688.668 & 3.468 & 692.137 \\
\hline Período & \multicolumn{7}{|c|}{ Variação (\% a.a.) } \\
\hline $2014-2019$ & 4,3 & 3,4 & 2,3 & 2,5 & 2,7 & $-10,9$ & 2,6 \\
\hline 2019-2024 & 7,1 & 5,5 & 5,0 & 4,5 & 5,2 & 10,4 & 5,2 \\
\hline $2014-2024$ & 5,7 & 4,4 & 3,6 & 3,5 & 3,9 & $-0,8$ & 3,9 \\
\hline
\end{tabular}

O ONS, em seu Planejamento de Carga anual, afirma que é esperada uma leve recuperação da economia em 2017, seguida de um crescimento mais forte a partir de 2018, como consequência da melhoria das expectativas dos agentes, proporcionando o início da retomada tanto do consumo quanto do investimento.

Para a SBPE (Sociedade Brasileira de Planejamento Energético), não restam dúvidas sobre o aumento da demanda por energia no mundo e sobre a necessidade de segurança de suprimento como um fator indispensável ao desenvolvimento das nações.

A partir das informações de mercado, a projeção para a geradoras termelétricas é de alto nível de despacho. Sabe-se que o alto valor de despacho de 2015 (80\%) foi afetado pela seca no Nordeste, no entanto, para o cenário realista da usina, o estudo não pode considerar esse alto valor, pois Itaqui teve um desempenho operacional muito superior a todos os outros anos, tendo sido 2015 seu melhor ano operacional.

Como dito na revisão de literatura, as termelétricas, em sua maioria, foram criadas para ficarem paradas na maior parte do tempo. Quando elas são muito solicitadas pelo ONS elas tendem a apresentar muitos defeitos operacionais, e, para a termelétrica Itaqui, não é diferente. Quando é muito solicitada pelo ONS, ela apresenta defeitos operacionais, diminuindo assim, a disponibilidade da usina. 
Considerando as informações acima, para Itaqui será estimado $70 \%$ de volume de despacho para os próximos anos.

\subsubsection{Receitas fixa e variável}

A receita fixa da usina é atualizada anualmente em novembro pelo IPCA desde o leilão $A-5$, no qual foram negociados $315 \mathrm{MW}$ de energia para o Governo. Em 2015 a receita fixa de Itaqui fechou em R\$ 359 milhões. Como esse item é indexado ao IPCA, as projeções foram realizadas com base no IPCA extraído dos Relatórios de Mercado Semanais do Focus, calculados pelo Banco Central do Brasil.

A receita variável é composta pelas seguintes variáveis: Combustível e O\&M. Estas variáveis compõem o $\mathrm{CVU}^{7}$ da usina.

A fim de realizar a projeção do CVU foram analisadas no mercado as estimativas até o ano de 2020 do preço do carvão e da taxa de câmbio (R\$/US\$), como pode ser observado na figura 7 .

- Variável Combustível - Projeção do custo de combustível realizada com base nos valores do Nymex (CIF ARA - Preço do carvão US\$/Ton), taxa de câmbio R\$/US\$ (Banco Central) e Fator i (valor fixo do leilão).

- Variável O\&M - Projeção do custo de O\&M realizada com base na taxa fixada no leilão que anualmente é ajustada pelo IPCA em novembro.

Figura 7 - Projeção CVU

\begin{tabular}{|c|c|c|c|c|c|c|c|}
\hline CVU & & 2015 & 2016E & 2017E & 2018E & 2019E & 2020E \\
\hline Preço do carvão (US\$/Ton) & Nymex (CIF ARA) & 52,85 & 46,4 & 40,9 & 40,5 & 39,8 & 39,8 \\
\hline Taxa de câmbio (R\$/US\$) & Banco Central & 3,78 & 4,14 & 4,28 & 4,33 & 4,32 & 4,41 \\
\hline Fator $\mathrm{i}$ & $51,6 \%$ & $51,6 \%$ & $51,6 \%$ & $51,6 \%$ & $51,6 \%$ & $51,6 \%$ & $51,6 \%$ \\
\hline Custo de combustível (R\$/MWh) & & 103,1 & 99,1 & 90,2 & 90,4 & 88,6 & 90,6 \\
\hline Custo O\&M (R\$/MWh) ${ }^{1}$ & $2015=18,79$ & 18,8 & 20,2 & 21,3 & 22,7 & 24,1 & 25,7 \\
\hline $\mathrm{CVU}(\mathrm{RS} / \mathrm{MWh})$ & & 121,9 & 119,3 & 111,5 & 113,0 & 112,7 & 116,3 \\
\hline Net CVU (R\$/MWh) ${ }^{2}$ & & 109,5 & 107,2 & 100,2 & 101,6 & 101,3 & 104,5 \\
\hline
\end{tabular}

Na tabela acima pode-se observar que para 2016 os Custos de Combustível estão estimados em R $\$ 99$ milhões e os Custos de O\&M R $\$ 20$ milhões. O CVU final líquido de 2016 projetado é de aproximadamente R\$/MWh 107 milhões.

${ }^{7}$ CVU - Custo Variável Único. 
A partir dessas premissas de CVU e da geração é calculada a receita variável.

\subsubsection{Custos Operacionais/ Despesas administrativas/ CAPEX}

Para cálculo dos valores de Custos Operacionais e de Despesas administrativas foram utilizados os números registrados no ITR 4T15, R\$ 102 milhões e R $\$ 4$ milhões, respectivamente, e projetados para todo o ano de 2015 , pois não foi encontrado o valor total de 2015 desse item na apresentação de resultados da empresa.

Para os próximos anos, de 2016 em diante os custos operacionais estão atrelados ao valor de geração por GWh da usina e inflacionados pelo IPCA. Isto é, quanto maior a geração de Itaqui, maiores serão seus custos operacionais, e vice-versa.

Para a projeção das despesas administrativas foi utilizado o mesmo valor de 2015, atualizado para os próximos anos pelo IPCA.

Utilizando como base $70 \%$ de despacho, para 2017, a projeção de Custos Operacionais foi estimada em aproximadamente $\mathrm{R} \$ 355$ milhões, enquanto as despesas administrativas ficaram em aproximadamente $\mathrm{R} \$ 20$ milhões.

Em 2015 aconteceram altos custos relacionados ao CAPEX devido à uma falha na correia transportadora de carvão. O valor total desse investimento foi de aproximadamente $\mathrm{R} \$ 10$ milhões. Para os próximos anos não foram projetados valores de CAPEX, pois a ENEVA não possui premissas definidas para reinvestimentos.

\subsubsection{Dívida}

De acordo com a informações do passivo da empresa, a usina possui $70 \%$ de capital de terceiros. O valor total de suas dívidas com o BNDES $^{8}$ e com o $\mathrm{BNB}^{9}$ é de $\mathrm{R} \$ 1.286 .000,00$. Como pode ser observado na figura 8 , as taxas de juros são diferentes para cada dívida indexadas ao IPCA e ao TJLP, somadas a percentuais fixos.

\footnotetext{
${ }^{8}$ BNDES - Banco Nacional de Desenvolvimento Econômico e Social

${ }^{9}$ BNB - Banco do Nordeste
} 
Figura 8 - Dívidas Itaqui

\begin{tabular}{|c|c|c|c|c|}
\hline Itaqui & 4TR15 & Taxa a.a. juros & $\mathbf{( \% )}$ & Vencimento \\
\hline BNDES (Direto) & 792,0 & TJLP+2,78\% & $7,8 \%$ & $15 / 06 / 2026$ \\
BNB & 198,9 & $10 \%$ & $10,0 \%$ & $15 / 12 / 2026$ \\
BNDES (Indireto) & 138,0 & IPCA+12,13\% & $18,3 \%$ & $15 / 06 / 2026$ \\
BNDES (Indireto) & 156,6 & TJLP+4,8\% & $9,8 \%$ & $15 / 06 / 2026$ \\
\hline Total & $\mathbf{1 2 8 6}$ & & $\mathbf{1 1 \%}$ & \\
\hline
\end{tabular}

Para projeção da dívida foi realizada a média das taxas de juros relacionadas a cada dívida descritas na figura acima. O valor de $11 \%$ é estimado até 2026 , ano de vencimento da dívida.

\subsubsection{Variação de Capital de Giro}

Para o cálculo da variação de capital de giro, cada qual item componente do cálculo teve sua premissa designada a receita líquida ou custo operacional.

Dessa forma, a projeção do item contas a receber foi realizada com base na variação da receita líquida. O item estoque foi estimado de acordo com os custos operacionais, assim como o item contas a pagar.

Pode-se observar na figura 9 que foram usadas as variações entre os anos para o cálculo da variação do capital de giro.

Figura 9 - Cálculo Variação de Capital de Giro

\begin{tabular}{|c|c|c|c|c|c|c|c|c|c|c|c|c|}
\hline & 2016 & 2017 & 2018 & 2019 & 2020 & 2021 & 2022 & 2023 & 2024 & 2025 & 2026 & 2027 \\
\hline Contas a receber & 101,6 & 101,6 & 105,9 & 109,8 & 115,4 & 122,8 & 130,7 & 139,2 & 148,2 & 157,8 & 167,9 & 178,8 \\
\hline Estoque & 69,2 & 69,2 & 72,1 & 74,7 & 78,6 & 83,6 & 89,0 & 94,8 & 100,9 & 107,4 & 114,4 & 121,8 \\
\hline Contas a pagar & $-61,9$ & $-61,9$ & $-64,5$ & $-66,8$ & $-70,2$ & $-74,8$ & $-79,6$ & $-84,8$ & $-90,2$ & $-96,1$ & $-102,3$ & $-108,9$ \\
\hline \multirow[t]{2}{*}{ Capital de Giro } & 108,9 & 108,9 & 113,6 & 117,7 & 123,7 & 131,7 & 140,2 & 149,2 & 158,9 & 169,1 & 180,0 & 191,7 \\
\hline & $-16,1$ & 0,0 & 4,6 & 4,1 & 6,0 & 8,0 & 8,5 & 9,1 & 9,6 & 10,3 & 10,9 & 11,6 \\
\hline Contas a receber & 0,2 & 0,2 & 0,2 & 0,2 & 0,2 & 0,2 & 0,2 & 0,2 & 0,2 & 0,2 & 0,2 & 0,2 \\
\hline Estoque & 0,2 & 0,2 & 0,2 & 0,2 & 0,2 & 0,2 & 0,2 & 0,2 & 0,2 & 0,2 & 0,2 & 0,2 \\
\hline Contas a pagar & 0,2 & 0,2 & 0,2 & 0,2 & 0,2 & 0,2 & 0,2 & 0,2 & 0,2 & 0,2 & 0,2 & 0,2 \\
\hline Receita líquida & 645,3 & 645,4 & 672,9 & 697,2 & 732,8 & 780,2 & 830,6 & 884,2 & 941,3 & 1002,1 & 1066,9 & 1135,8 \\
\hline Custos operacionais & $-354,8$ & $-354,8$ & $-369,9$ & $-383,3$ & $-402,9$ & $-428,9$ & $-456,6$ & $-486,1$ & $-517,5$ & $-550,9$ & $-586,5$ & $-624,4$ \\
\hline
\end{tabular}

\subsubsection{CAPM}

A projeção da taxa livre de risco foi utilizada com base nos títulos do tesouro americano com vencimento de 20 anos. Foi realizada a média anual de 20 anos. O valor final foi de $4,63 \%$. 
A taxa de retorno de mercado foi calculada com base na Standart \& Poors 500. Foi realizada média anual de 20 anos, de 1996 a 2016, última data (01/03/2016). O valor final foi de 9,2\%.

O Beta do setor de energia dos EUA, calculado por DAMODARAN (2016), foi de 0,8. No entanto, é preciso incluir no risco do negócio o efeito da dívida. Por isso, foi necessário realizar a desalavancagem do beta do setor de energia dos EUA. E realavancá-lo com o valor da dívida sobre o patrimônio líquido de Itaqui. O Beta final encontrado foi de 1,52, conforme a figura 10.

\section{Figura 10 - Coeficiente beta Itaqui}

\begin{tabular}{|l|c|c|c|c|c|c|c|c|} 
Nome da Indústria & Empresas & Beta & $\boldsymbol{P L}$ & Desalavancado & Alavancado Itaqui & \multicolumn{1}{|c|}{ Dívida } & Impostos \\
\hline Energia & 73 & 0,8 & $7,05 \%$ & 0,58 & 1,52 & $3,52 \%$ & $23,38 \%$ \\
\hline
\end{tabular}

Fonte: Damodaran 2016. Adaptado pelo autor.

Para ajustar a realidade do país e projetar o risco de inadimplência do Brasil foi somado o Risco Brasil (4,8\%). Esse valor é a média dos últimos 20 anos.

Como todo o cálculo foi realizado com base nas taxas americanas, ele estava na moeda americana. A fim de transformar o cálculo para a moeda brasileira, foi encontrada uma média de 20 anos da inflação brasileira através do IBGE $(6,78 \%)$ e americana através do US inflation calculator $(2,19 \%)$.

Após realizar todos os cálculos do CAPM, o valor final encontrado para o custo de capital próprio, e que será utilizado como a taxa de retorno do acionista foi de $20,84 \%$.

\subsubsection{Resultados dos Índices Financeiros}

Os índices financeiros indicaram que a empresa teve em 2015 seu melhor ano. 
Figura 11 - Resultados índices financeiros

\begin{tabular}{|l|c|c|c|}
\hline Índices Finance iros & $\mathbf{2 0 1 3}$ & $\mathbf{2 0 1 4}$ & $\mathbf{2 0 1 5}$ \\
\hline Liquidez Corrente & 0,5 & 0,8 & 2,0 \\
Liquidez Seca & 0,4 & 0,5 & 1,3 \\
Liquidez Geral & 0,2 & 0,3 & 0,3 \\
Margem EBITDA & 0,2 & $-0,2$ & 0,4 \\
Endividamento Geral & 0,7 & 0,7 & 0,7 \\
ROE & $-0,2$ & $-0,1$ & 0,2 \\
\hline
\end{tabular}

Os índices financeiros da usina demonstram uma significativa melhora em seu desempenho quanto à performance operacional. A Margem EBITDA da empresa teve um significativo aumento de 2013 a 2015 devido à alta performance de Itaqui em 2015. Quando foi chamada a despachar pelo o ONS, a usina correspondeu todas as vezes e obteve $100 \%$ de disponibilidade.

O endividamento geral é de $70 \%$ e esse percentual se mantém até que Itaqui quite suas grandes dívidas com o BNB e BNDES.

A liquidez corrente tem uma grande melhora em 2015 devido à rolagem da de um empréstimo que estava no curto prazo e que passou para longo prazo. $O$ valor do empréstimo era de aproximadamente $\mathrm{R} \$ 90$ milhões. Dessa forma, a liquidez corrente teve uma significativa melhora em 2015, saindo de 0,5 em 2013 para 2,0 em 2015.

\subsection{Descrição dos resultados}

Nesse estudo de caso foi realizada uma análise de sensibilidade dos valores justos encontrados a partir do modelo de Fluxo de Caixa Descontado.

Nesse último ano de 2015 , os resultados da usina de Itaqui quanto à performance operacional foram os melhores desde que a usina começou a operar. Devido à falta de chuva na região Nordeste, região cuja usina vende energia no Mercado Livre (ACL).

Para melhor analisar o valor da usina de Itaqui serão elaborados três cenários com diferentes previsões de despacho, de acordo com a figura 12. 
Figura 12 - Cenários

\begin{tabular}{|c|c|}
\hline Cenários & Despacho \\
\hline Otimista & $95 \%$ \\
Realista & $70 \%$ \\
Pessimista & $40 \%$ \\
\hline
\end{tabular}

\subsubsection{Análise Cenário Realista}

O cenário base, descrito no item de premissas operacionais, determinou nível de $70 \%$ de despacho para a usina de Itaqui. O valor justo estimado encontrado, utilizando $70 \%$ de despacho, de 2016 a 2027 foi de aproximadamente $\mathrm{R} \$ 638$ milhões.

\section{Figura 13 - DRE Cenário Realista}

\begin{tabular}{|c|c|c|c|c|c|c|c|c|c|c|c|c|}
\hline \multirow{2}{*}{ R\$ MM - DRE } & & & & & & & & & & & & \\
\hline & 2016E & 2017E & 2018E & 2019E & $2020 \mathrm{E}$ & 2021E & 2022E & 2023E & 2024E & 2025E & 2026E & 2027E \\
\hline Disponibilidade (ONS) & $100 \%$ & $100 \%$ & $100 \%$ & $100 \%$ & $100 \%$ & $100 \%$ & $100 \%$ & $100 \%$ & $100 \%$ & $100 \%$ & $100 \%$ & $100 \%$ \\
\hline Despacho GE & $70 \%$ & $70 \%$ & $70 \%$ & $70 \%$ & $70 \%$ & $70 \%$ & $70 \%$ & $70 \%$ & $70 \%$ & $70 \%$ & $70 \%$ & $70 \%$ \\
\hline Geração Bruta (GWh) & 3.024 & 3.024 & 3.024 & 3.024 & 3.024 & 3.024 & 3.024 & 3.024 & 3.024 & 3.024 & 3.024 & 3.024 \\
\hline (-)Perdas de TransmisR & 2016E & 2017E & 2018E & 2019E & 2020E & $2021 E$ & 2022E & 2023E & 2024E & 2025E & 2026E & 2027E \\
\hline Despacho GE & $70 \%$ & $70 \%$ & $70 \%$ & $70 \%$ & $70 \%$ & $70 \%$ & $70 \%$ & $70 \%$ & $70 \%$ & $70 \%$ & $70 \%$ & $70 \%$ \\
\hline Geração Bruta (GWh) & 3.024 & 3.024 & 3.024 & 3.024 & 3.024 & 3.024 & 3.024 & 3.024 & 3.024 & 3.024 & 3.024 & 3.024 \\
\hline (-)Perdas de Transmissão e Consumo interno (12\%) & -4 & -4 & -4 & -4 & -4 & -4 & -4 & -4 & -4 & -4 & -4 & -4 \\
\hline Geração Líquida (GWh) & 3.020 & 3.020 & 3.020 & 3.020 & 3.020 & 3.020 & 3.020 & 3.020 & 3.020 & 3.020 & 3.020 & 3.020 \\
\hline ACR & 2.798 & 2.798 & 2.798 & 2.798 & 2.798 & 2.798 & 2.798 & 2.798 & 2.798 & 2.798 & 2.798 & 2.798 \\
\hline ACL & 222 & 222 & 222 & 222 & 222 & 222 & 222 & 222 & 222 & 222 & 222 & 222 \\
\hline Receita Bruta & 719,0 & 719,1 & 749,7 & 776,9 & 816,5 & 869,3 & 925,4 & 985,2 & $1.048,8$ & $1.116,6$ & $1.188,7$ & $1.265,5$ \\
\hline 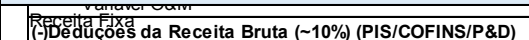 & $385,3,7$ & 407,4 & $\begin{array}{l}43,4 \\
436,8\end{array}$ & 469,4 & $\begin{array}{ll}494,2 \\
-83,7\end{array}$ & $-82,19$ & $\begin{array}{l}5567 \\
-94,97\end{array}$ & $-109,07$ & $-107,59$ & \begin{tabular}{|l|l|}
$671,4,7$ \\
$-114,5$
\end{tabular} & \begin{tabular}{|l|}
$121,8,8,1$ \\
$-121,8$
\end{tabular} & $-129,7,3$ \\
\hline 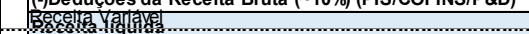 & $3 x_{3}^{3}$ & 36454 & 3623 & $\ldots$ & 335,8 & $7862^{3}$ & 836,6 & $-823,25$ & $94,3,9$ & $1.0024,9$ & $1.065,2,6$ & $1.135,8,2$ \\
\hline 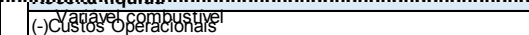 & 27384,2 & 25203,8 & 2529,9 & 247,9 & $-453,4$ & $-599,8$ & $-582,2^{2}$ & $-589,98$ & $-625,5,5$ & $-660,3,6$ & $-70,3,3,0$ & $-755^{3,92,8}$ \\
\hline 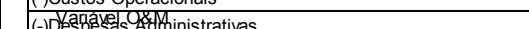 & 50,44 & $590_{5}$ & 63,4 & 625 & $-31,9$ & $-36,5$ & 815 & -2868 & $-32,4$ & $-329,3$ & $-34^{104,7}$ & $-36,11,4$ \\
\hline (-) 中edysoóss da Receita Bruta ( 10\%) (PIS/COFINS/P\&D) & -1360 & $=2390$ & $-76 \sigma^{8} 8$ & -7806 & -283.6 & -289.7 & $-20949^{9}$ & -20650 & $-20100,5$ & $-20344,5$ & $-20 d^{2} 31,8$ & $-200^{129,7}$ \\
\hline Receita líquida & 645,3 & 645,4 & 672,9 & 697,2 & 732,8 & 780,2 & 830,6 & 884,2 & 941,3 & $1.002,1$ & $1.066,9$ & $1.135,8$ \\
\hline (-)Custos Operacionais & $-382,2$ & $-403,8$ & $-429,9$ & $-457,7$ & $-487,2$ & $-518,7$ & $-552,2$ & $-587,9$ & $-625,8$ & $-666,3$ & $-709,3$ & $-755,1$ \\
\hline (-)Despesas Administrativas & $-18,4$ & $-19,5$ & $-20,8$ & $-22,1$ & $-23,5$ & $-25,0$ & $-26,7$ & $-28,4$ & $-30,2$ & $-32,2$ & $-34,2$ & $-36,5$ \\
\hline (-)Depreciação & $-200,0$ & $-200,0$ & $-200,0$ & $-200,0$ & $-200,0$ & $-200,0$ & $-200,0$ & $-200,0$ & $-200,0$ & $-200,0$ & $-200,0$ & $-200,0$ \\
\hline EBITDA & 244,7 & 222,1 & 222,2 & 217,5 & 222,1 & 236,4 & 251,7 & 268,0 & 285,3 & 303,7 & 323,3 & 344,2 \\
\hline (-)Despesas financeiras (juros) & $-147,4$ & $-135,2$ & $-122,9$ & $-110,6$ & $-98,3$ & $-86,0$ & $-73,7$ & $-61,4$ & $-49,1$ & $-36,9$ & $-24,6$ & $-12,3$ \\
\hline LAIR & 97,3 & 87,0 & 99,4 & 106,9 & 123,8 & 150,4 & 178,0 & 206,5 & 236,1 & 266,8 & 298,8 & 331,9 \\
\hline (-)Impostos & 0,0 & 0,0 & 0,0 & 0,0 & 0,0 & 0,0 & 0,0 & 0,0 & 0,0 & 0,0 & 0,0 & 0,0 \\
\hline Lucro líquido & 97,3 & 87,0 & 99,4 & 106,9 & 123,8 & 150,4 & 178,0 & 206,5 & 236,1 & 266,8 & 298,8 & 331,9 \\
\hline (+)Depreciação & 200,0 & 200,0 & 200,0 & 200,0 & 200,0 & 200,0 & 200,0 & 200,0 & 200,0 & 200,0 & 200,0 & 200,0 \\
\hline \multicolumn{13}{|l|}{ (-)CAPEX } \\
\hline (-) Pagamento principal de dividas & $-254,6$ & $-242,3$ & $-230,0$ & $-217,7$ & $-205,4$ & $-193,1$ & $-180,8$ & $-168,6$ & $\begin{array}{l}-156,3 \\
\end{array}$ & $\begin{array}{l}-144,0 \\
\end{array}$ & $\begin{array}{l}-131,7 \\
\end{array}$ & $-119,4$ \\
\hline (-) Variação Capital de Giro & 14,8 & $-0,5$ & $-4,9$ & $-4,4$ & $-6,3$ & $-8,2$ & $-8,7$ & $-9,2$ & $-9,8$ & $-10,5$ & $-11,1$ & $-11,9$ \\
\hline
\end{tabular}

FCA
VALOR PRESENTE 


\subsubsection{Análise de Cenário Pessimista}

Para compor o cenário pessimista, as premissas de despacho foram reduzidas a partir de 2016 até 2027 para 40\%.

$\mathrm{Na}$ região nordeste, a partir de março, o Operador Nacional do Sistema ordenou que as termelétricas que possuem o CVU mais caro da região fossem desligadas à noite e durante o final de semana. Com isso, a usina receberia a receita fixada no leilão e sua receita variável seria prejudicada pela falta de despacho por ordem de mérito ${ }^{10}$.

Sabe-se que a usina de Itaqui tem grandes problemas operacionais quando é solicitada muitas vezes a despachar pelo ONS. Por diversas vezes Itaqui teve sua disponibilidade reduzida, porque quando foi chamada a despachar pelo ONS não esteve disponível devido à problemas operacionais.

Quando religada, após uma parada por problemas técnicos, Itaqui utiliza um alto valor de diesel e outros custos de operação e manutenção que fazem com que a usina quando parada forneça um maior retorno do que quando está sendo chamada muitas vezes a despachar.

Considerando um valor muito baixo de despacho, nível de $40 \%$, o valor justo da usina sobe para aproximadamente $R \$ 1$ bilhão. $O$ que corrobora a afirmativa de que as termelétricas foram criadas para despacharem pouco.

Figura 14 - DRE Cenário Pessimista

\begin{tabular}{|c|c|c|c|c|c|c|c|c|c|c|c|c|}
\hline$R \$ M M$ - DRE & 2016E & 2017E & 2018E & 2019E & $2020 \mathrm{E}$ & 2021E & 2022E & 2023E & 2024E & 2025E & 2026E & 2027E \\
\hline Despacho GE & $40 \%$ & $40 \%$ & $40 \%$ & $40 \%$ & $40 \%$ & $40 \%$ & $40 \%$ & $40 \%$ & $40 \%$ & $40 \%$ & $40 \%$ & $40 \%$ \\
\hline Geração Bruta (GWh) & 1.728 & 1.728 & 1.728 & 1.728 & 1.728 & 1.728 & 1.728 & 1.728 & 1.728 & 1.728 & 1.728 & 1.728 \\
\hline (-)Perdas de Transmissão e Consumo interno (12\%) & -2 & -2 & -2 & -2 & -2 & -2 & -2 & -2 & -2 & -2 & -2 & -2 \\
\hline Geração Líquida (GWh) & 1.726 & 1.726 & 1.726 & 1.726 & 1.726 & 1.726 & 1.726 & 1.726 & 1.726 & 1.726 & 1.726 & 1.726 \\
\hline ACR & 1.599 & 1.599 & 1.599 & 1.599 & 1.599 & 1.599 & 1.599 & 1.599 & 1.599 & 1.599 & 1.599 & 1.599 \\
\hline ACL & 127 & 127 & 127 & 127 & 127 & 127 & 127 & 127 & 127 & 127 & 127 & 127 \\
\hline Receita Bruta & 576,0 & 585,4 & 614,1 & 641,7 & 677,1 & 720,8 & 767,4 & 817,0 & 869,7 & 925,9 & 985,7 & $1.049,4$ \\
\hline Receita Fixa & 385,3 & 407,1 & 433,4 & 461,4 & 491,2 & 522,9 & 556,7 & 592,7 & 630,9 & 671,7 & 715,1 & 761,3 \\
\hline Receita Variável & 190,7 & 178,3 & 180,8 & 180,3 & 185,9 & 197,9 & 210,7 & 224,3 & 238,8 & 254,2 & 270,7 & 288,1 \\
\hline Variável combustível & 158,5 & 144,3 & 144,5 & 141,7 & 144,8 & 154,2 & 164,1 & 174,7 & 186,0 & 198,0 & 210,8 & 224,5 \\
\hline Variável O\&M & 32,2 & 34,1 & 36,3 & 38,6 & 41,1 & 43,7 & 46,6 & 49,6 & 52,8 & 56,2 & 59,8 & 63,7 \\
\hline \multicolumn{13}{|l|}{$\begin{array}{l}\text { Liquidação no ACL } \\
\text { Liquidação de Lastro } \\
\text { Ajuste de meses anteriores }\end{array}$} \\
\hline (-)Deduções da Receita Bruta ( 10\%) (PIS/COFINS/P\&D) & $-59,0$ & $-60,0$ & $-63,0$ & $-65,8$ & $-69,4$ & $-73,9$ & $-78,7$ & $-83,7$ & $-89,1$ & $-94,9$ & $-101,0$ & $-107,6$ \\
\hline Receita líquida & 517,0 & 525,4 & 551,2 & 575,9 & 607,7 & 646,9 & 688,7 & 733,2 & 780,6 & 831,0 & 884,7 & 941,9 \\
\hline$(-)$ Custos Operacionais & $-218,4$ & $-230,7$ & $-245,6$ & $-261,5$ & $-278,4$ & $-296,4$ & $-315,5$ & $-335,9$ & $-357,6$ & $-380,7$ & $-405,3$ & $-431,5$ \\
\hline$(-)$ Despesas Administrativas & $-18,4$ & $-19,5$ & $-20,8$ & $-22,1$ & $-23,5$ & $-25,0$ & $-26,7$ & $-28,4$ & $-30,2$ & $-32,2$ & $-34,2$ & $-36,5$ \\
\hline (-)Depreciação & $-200,0$ & $-200,0$ & $-200,0$ & $-200,0$ & $-200,0$ & $-200,0$ & $-200,0$ & $-200,0$ & $-200,0$ & $-200,0$ & $-200,0$ & $-200,0$ \\
\hline EBITDA & 280,1 & 275,2 & 284,8 & 292,3 & 305,8 & 325,5 & 346,5 & 368,9 & 392,8 & 418,1 & 445,1 & 473,9 \\
\hline$(-)$ Despesas financeiras (juros) & $-147,4$ & $-135,2$ & $-122,9$ & $-110,6$ & $-98,3$ & $-86,0$ & $-73,7$ & $-61,4$ & $-49,1$ & $-36,9$ & $-24,6$ & $-12,3$ \\
\hline LAIR & 132,7 & 140,0 & 161,9 & 181,7 & 207,5 & 239,5 & 272,8 & 307,5 & 343,6 & 381,3 & 420,6 & 461,6 \\
\hline (-)Impostos & 0,0 & 0,0 & 0,0 & 0,0 & 0,0 & 0,0 & 0,0 & 0,0 & 0,0 & 0,0 & 0,0 & 0,0 \\
\hline Lucro líquido & 132,7 & 140,0 & 161,9 & 181,7 & 207,5 & 239,5 & 272,8 & 307,5 & 343,6 & 381,3 & 420,6 & 461,6 \\
\hline (+)Depreciação & 200,0 & 200,0 & 200,0 & 200,0 & 200,0 & 200,0 & 200,0 & 200,0 & 200,0 & 200,0 & 200,0 & 200,0 \\
\hline \multicolumn{13}{|l|}{ (-)CAPEX } \\
\hline (-) Pagamento principal de dívidas & $-254,6$ & $-242,3$ & $-230,0$ & $-217,7$ & $-205,4$ & $-193,1$ & $-180,8$ & $-168,6$ & $-156,3$ & $-144,0$ & $-131,7$ & $-119,4$ \\
\hline (-) Variação Capital de Giro & 38,6 & $-1,6$ & $-4,4$ & $-4,2$ & $-5,4$ & $-6,6$ & $-7,0$ & $-7,5$ & $-8,0$ & $-8,5$ & $-9,0$ & $-9,6$ \\
\hline FCA & 110,7 & 96,1 & 127,5 & 159,7 & 196,6 & 239,8 & 284,9 & 331,5 & 379,4 & 428,8 & 479,8 & 532,6 \\
\hline VALOR PRESENTE & 1039,24 & & & & & & & & & & & \\
\hline
\end{tabular}




\subsubsection{Análise de Cenário Otimista}

Para compor o cenário otimista a premissa de despacho foi projetada a partir de 2016 a 2027 a 95\%.

No ano de 2015, a grande performance operacional da usina de Itaqui foi objeto de destaque no release do quarto trimestre da Eneva. Devido à falta de chuva na região nordeste, a usina foi acionada por todo tempo. E por todo tempo em que foi chamada no último mês registrado no último release de 2015 da Eneva, ela esteve disponível não apresentando problemas. Analisando o histórico da usina, pode-se concluir que esse cenário descreve um desempenho extraordinário de Itaqui.

Com isso, o cenário otimista projeta esse ótimo cenário para a usina caracterizado pela alta performance operacional de Itaqui, pela falta de chuva e grande necessidade de acionamento pelo ONS.

Nota-se que o valor justo da empresa diminui para aproximadamente $\mathrm{R} \$$ 304 milhões quando é acionada por tantas vezes pelo o ONS, porque seus custos variáveis são mais altos do que a receita variável obtida. Para a usina de Itaqui, não compensa operar full time, porque ela não tem um bom desempenho operacional, possuindo, dessa forma, altos custos operacionais.

\section{Figura 15 - DRE Cenário Otimista}




\begin{tabular}{|c|c|c|c|c|c|c|c|c|c|c|c|c|}
\hline R\$ MM - DRE & 2016E & 2017E & 2018E & 2019E & 2020E & 2021E & 2022E & 2023E & 2024E & 2025E & 2026E & 2027E \\
\hline Despacho GE & $95 \%$ & $95 \%$ & $95 \%$ & $95 \%$ & $95 \%$ & $95 \%$ & $95 \%$ & $95 \%$ & $95 \%$ & $95 \%$ & $95 \%$ & $95 \%$ \\
\hline Geração Bruta (GWh) & 4.104 & 4.104 & 4.104 & 4.104 & 4.104 & 4.104 & 4.104 & 4.104 & 4.104 & 4.104 & 4.104 & 4.104 \\
\hline (-)Perdas de Transmissão e Consumo interno (12\%) & -5 & -5 & -5 & -5 & -5 & -5 & -5 & -5 & -5 & -5 & -5 & -5 \\
\hline Geração Líquida (GWh) & 4.099 & 4.099 & 4.099 & 4.099 & 4.099 & 4.099 & 4.099 & 4.099 & 4.099 & 4.099 & 4.099 & 4.099 \\
\hline ACR & 3.798 & 3.798 & 3.798 & 3.798 & 3.798 & 3.798 & 3.798 & 3.798 & 3.798 & 3.798 & 3.798 & 3.798 \\
\hline ACL & 301 & 301 & 301 & 301 & 301 & 301 & 301 & 301 & 301 & 301 & 301 & 301 \\
\hline Receita Bruta & 838,2 & 830,6 & 862,7 & 889,5 & 932,7 & 993,0 & $1.057,1$ & $1.125,4$ & $1.198,1$ & $1.275,5$ & $1.357,9$ & $1.445,6$ \\
\hline Receita Fixa & 385,3 & 407,1 & 433,4 & 461,4 & 491,2 & 522,9 & 556,7 & 592,7 & 630,9 & 671,7 & 715,1 & 761,3 \\
\hline Receita Variável & 453,0 & 423,5 & 429,3 & 428,2 & 441,5 & 470,0 & 500,4 & 532,7 & 567,2 & 603,8 & 642,8 & 684,3 \\
\hline Variável combustível & 376,4 & 342,6 & 343,2 & 336,5 & 343,9 & 366,2 & 389,8 & 415,0 & 441,8 & 470,4 & 500,7 & 533,1 \\
\hline Variável O\&M & 76,5 & 80,9 & 86,1 & 91,7 & 97,6 & 103,9 & 110,6 & 117,7 & 125,3 & 133,4 & 142,1 & 151,2 \\
\hline \multicolumn{13}{|l|}{$\begin{array}{l}\text { Liquidação no ACL } \\
\text { Liquidação de Lastro } \\
\text { Ajuste de meses anteriores }\end{array}$} \\
\hline (-)Deduções da Receita Bruta ( 10\%) (PIS/COFINS/P\&D) & $-85,9$ & $-85,1$ & $-88,4$ & $-91,2$ & $-95,6$ & $-101,8$ & $-108,4$ & $-115,4$ & $-122,8$ & $-130,7$ & $-139,2$ & $-148,2$ \\
\hline Receita líquida & 752,3 & 745,4 & 774,3 & 798,4 & 837,1 & 891,2 & 948,8 & $1.010,0$ & $1.075,3$ & $1.144,8$ & $1.218,7$ & $1.297,4$ \\
\hline (-)Custos Operacionais & $-518,7$ & $-548,0$ & $-583,4$ & $-621,1$ & $-661,2$ & $-703,9$ & $-749,4$ & $-797,8$ & $-849,4$ & $-904,2$ & $-962,6$ & $-1.024,8$ \\
\hline (-)Despesas Administrativas & $-18,4$ & $-19,5$ & $-20,8$ & $-22,1$ & $-23,5$ & $-25,0$ & $-26,7$ & $-28,4$ & $-30,2$ & $-32,2$ & $-34,2$ & $-36,5$ \\
\hline (-)Depreciação & $-200,0$ & $-200,0$ & $-200,0$ & $-200,0$ & $-200,0$ & $-200,0$ & $-200,0$ & $-200,0$ & $-200,0$ & $-200,0$ & $-200,0$ & $-200,0$ \\
\hline EBITDA & 215,2 & 177,9 & 170,1 & 155,2 & 152,4 & 162,2 & 172,7 & 183,8 & 195,7 & 208,4 & 221,8 & 236,1 \\
\hline (-)Despesas financeiras (juros) & $-147,4$ & $-135,2$ & $-122,9$ & $-110,6$ & $-98,3$ & $-86,0$ & $-73,7$ & $-61,4$ & $-49,1$ & $-36,9$ & $-24,6$ & $-12,3$ \\
\hline LAIR & 67,8 & 42,8 & 47,2 & 44,6 & 54,1 & 76,2 & 99,0 & 122,4 & 146,6 & 171,5 & 197,2 & 223,9 \\
\hline (-)Impostos & 0,0 & 0,0 & 0,0 & 0,0 & 0,0 & 0,0 & 0,0 & 0,0 & 0,0 & 0,0 & 0,0 & 0,0 \\
\hline Lucro líquido & 67,8 & 42,8 & 47,2 & 44,6 & 54,1 & 76,2 & 99,0 & 122,4 & 146,6 & 171,5 & 197,2 & 223,9 \\
\hline (+)Depreciação & 200,0 & 200,0 & 200,0 & 200,0 & 200,0 & 200,0 & 200,0 & 200,0 & 200,0 & 200,0 & 200,0 & 200,0 \\
\hline \multicolumn{13}{|l|}{ (-)CAPEX } \\
\hline (-) Pagamento principal de dívidas & $-254,6$ & $-242,3$ & $-230,0$ & $-217,7$ & $-205,4$ & $-193,1$ & $-180,8$ & $-168,6$ & $-156,3$ & $-144,0$ & $-131,7$ & $-119,4$ \\
\hline (-) Variação Capital de Giro & $-4,9$ & 0,5 & $-5,3$ & $-4,6$ & $-7,0$ & $-9,5$ & $-10,1$ & $-10,7$ & $-11,4$ & $-12,1$ & $-12,9$ & $-13,8$ \\
\hline FCA & 8,2 & 1, & $11, \mathrm{~s}$ & 22,3 & 41,7 & 73,6 & 108,0 & 143,1 & 178,9 & 215,4 & 252,6 & 290,7 \\
\hline VALOR PRESENTE & 303,60 & & & & & & & & & & & \\
\hline
\end{tabular}

\subsubsection{Resultado dos Cenários}

Após realizar a projeção dos cenários, é possível identificar, a partir dos valores justos encontrados, que os cenários se comportam em direção oposta em relação às análises tradicionais. Geralmente, quando é realizada a projeção do cenário otimista, o valor justo registrado é maior do que o pessimista, pois a premissa utilizada tende a favorecer o aumento desse valor.

Nesse estudo, pode ser observado que quanto maior o despacho, menor é o valor justo da usina. $\mathrm{Na}$ figura 16 , estão descritos os valores justos encontrados em cada cenário. O menor valor encontrado foi de aproximadamente $\mathrm{R} \$ 304$ milhões no cenário otimista quando há um maior despacho de energia. O melhor cenário é o pessimista, no qual a usina valeria aproximadamente $\mathrm{R} \$ 1$ bilhão, despachando uma média de $40 \%$ de energia. 
Conclui-se que, despachar mais, para Itaqui, não melhora seus fluxos de caixa, nem traz mais valor ao projeto nas condições atuais previstas nesse modelo.

Figura 16 - Análise de Sensibilidade - Resultados

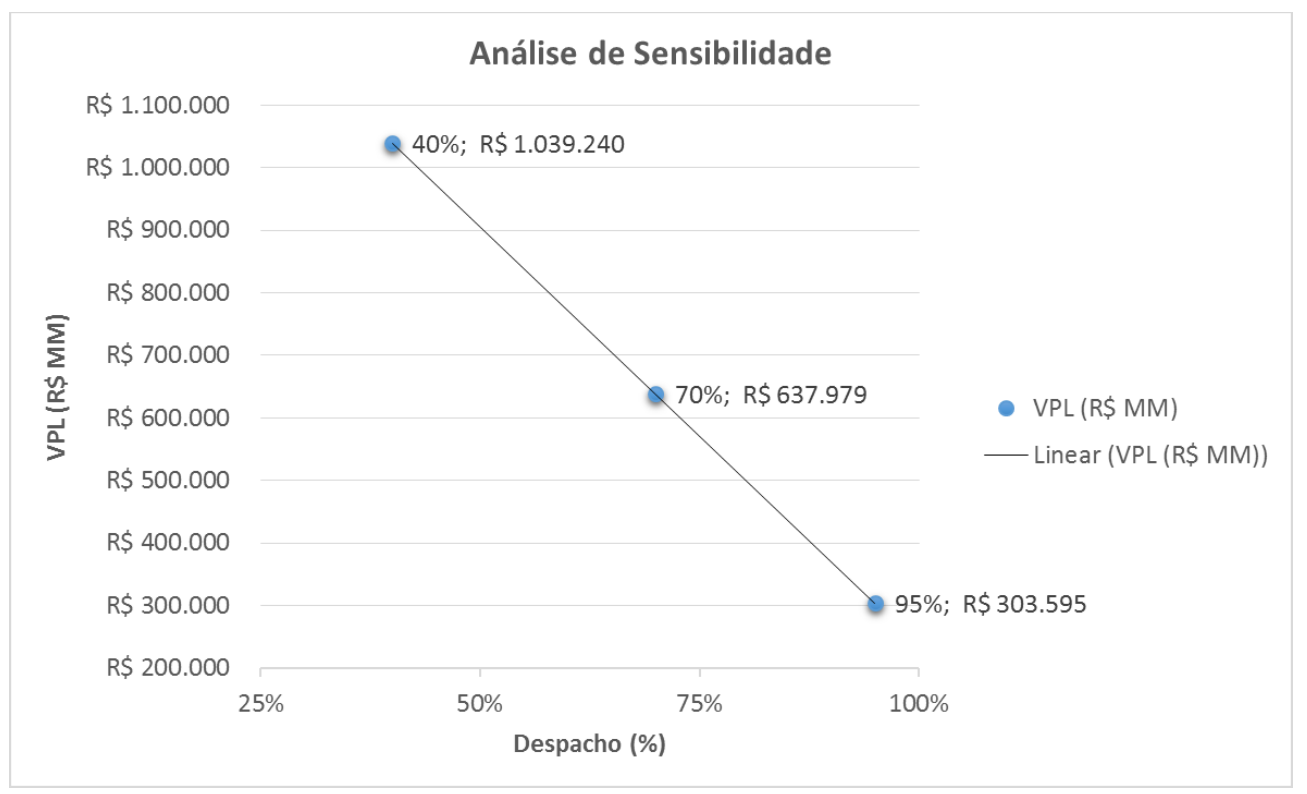




\section{Conclusão e recomendação para novos estudos}

A partir do resultado encontrado no cenário realista da usina, pode-se concluir que o valor justo estimado para Itaqui, de acordo com a metodologia do Fluxo de Caixa descontado, é de aproximadamente $\mathrm{R} \$ 638$ milhões.

Após analisar o contexto em que a usina se insere, é possível entender que a priori as termelétricas foram construídas somente para atuarem com a finalidade de "proteger" o sistema. No entanto, atualmente, pode-se observar que as termelétricas são inerentes ao sistema, permanecendo ligadas por quase todo o tempo.

Por isso, vale salientar que, após analisar os cenários realista, pessimista e otimista, nos quais foram alteradas somente as premissas de despacho, conclui-se que o comportamento dos cenários atua em sentido oposto às análises tradicionais. Tendo em vista que quanto maior o despacho, menor será o valor justo encontrado para a usina, e vice-versa.

Itaqui possui o maior valor justo ( $\mathrm{R} \$ 1$ bilhão) quando permanece com um baixo nível de despacho, $40 \%$ projetado no cenário pessimista. Enquanto no cenário otimista, o valor justo da empresa com 95\% de despacho é de $\mathrm{R} \$ 304$ milhões.

A usina do Maranhão se encaixa no perfil das termelétricas brasileiras, pois de acordo com os resultados obtidos, Itaqui possui o maior valor justo no cenário pessimista quando permanece com o menor nível de despacho. Isso significa que ela foi projetada somente para ser acionada em caso de necessidade, "protegendo" o sistema, e não para operar por todo o tempo.

$O$ resultado desse trabalho difere totalmente das outras avaliações de ativos tendo em vista que os cenários não correspondem às verdadeiras expectativas. O otimista não é o que traz maior valor a usina e sim o que destrói o seu valor. O pessimista é o cenário no qual a usina vale mais.

O paradoxo descrito acima ressalta a importância em estudar e analisar o caso das termelétricas brasileiras que são construídas, em sua maioria, para permanecerem paradas na maior parte do tempo. Por que construir uma termelétrica a fim de que ela fique parada na maior parte do tempo? Por que não construir uma usina que consiga gerar muito e com isso ela possa lucrar com 
sua geração? Por que as usinas são tão ruins e quebram tanto quando estão operando por todo o tempo?

Podem ser analisadas nos próximos estudos as penalidades sob as quais as usinas estão submetidas caso não despachem quando a ONS solicitar. Essa penalidade é conhecida como ADOMP e não foi analisada nesse trabalho. Os próximos estudos deveriam analisar essa penalidade, e fazer os cálculos de quanto ela receberia se não gerasse nada, somente recebendo a receita fixa até o fim do período de concessão, projetando também a receita do mercado livre. 


\section{Anexos}

1 - Treasury Bond - 20 anos

\begin{tabular}{|c|c|}
\hline Date & Value \\
\hline Jan 1, 2016 & $2,49 \%$ \\
\hline Jan 1, 2015 & $2,20 \%$ \\
\hline Jan 1, 2014 & $3,52 \%$ \\
\hline Jan 1, 2013 & $2,68 \%$ \\
\hline Jan 1, 2012 & $2,70 \%$ \\
\hline Jan 1, 2011 & $4,28 \%$ \\
\hline Jan 1, 2010 & $4,50 \%$ \\
\hline Jan 1, 2009 & $3,46 \%$ \\
\hline Jan 1, 2008 & $4,35 \%$ \\
\hline Jan 1, 2007 & $4,95 \%$ \\
\hline Jan 1, 2006 & $4,65 \%$ \\
\hline Jan 1, 2005 & $4,77 \%$ \\
\hline Jan 1, 2004 & $5,01 \%$ \\
\hline Jan 1, 2003 & $5,02 \%$ \\
\hline Jan 1, 2002 & $5,69 \%$ \\
\hline Jan 1, 2001 & $5,65 \%$ \\
\hline Jan 1, 2000 & $6,86 \%$ \\
\hline Jan 1, 1999 & $5,45 \%$ \\
\hline Jan 1, 1998 & $5,88 \%$ \\
\hline Jan 1, 1997 & $6,91 \%$ \\
\hline \multicolumn{2}{|c|}{ JaII 1, 1990 0,11\% } \\
\hline
\end{tabular}


2 - S\&P 500

\begin{tabular}{|l|r|r|r|r|r|r|r|}
\hline Data & Último Abertura & Máxima & Mínima & Vol. & Var\% & \\
\hline $\mathbf{0 1 . 0 3 . 2 0 1 6}$ & 2059,74 & 1937.09 & 2072.21 & 1937.09 & - & $6.60 \%$ & $-0,4 \%$ \\
\hline $\mathbf{0 1 . 0 3 . 2 0 1 5}$ & 2067,89 & 2105.23 & 2117.52 & 2039.69 & $--1.74 \%$ & $10 \%$ \\
\hline $\mathbf{0 1 . 0 3 . 2 0 1 4}$ & 1872,34 & 1857.68 & 1883.97 & 1834.44 & - & $\mathbf{0 . 6 9} \%$ & $19 \%$ \\
\hline $\mathbf{0 1 . 0 3 . 2 0 1 3}$ & 1569,19 & 1514.68 & 1570.28 & 1501.48 & - & $-3.60 \%$ & $11 \%$ \\
\hline $\mathbf{0 1 . 0 3 . 2 0 1 2}$ & 1408,47 & 1365.90 & 1419.15 & 1340.03 & - & $3.13 \%$ & $6 \%$ \\
\hline $\mathbf{0 1 . 0 3 . 2 0 1 1}$ & 1325,83 & 1328.64 & 1332.28 & 1249.05 & $--0.10 \%$ & $13 \%$ \\
\hline $\mathbf{0 1 . 0 3 . 2 0 1 0}$ & 1169,43 & 1105.36 & 1180.69 & 1105.36 & - & $5.88 \%$ & $47 \%$ \\
\hline $\mathbf{0 1 . 0 3 . 2 0 0 9}$ & 797,87 & 729.57 & 832.98 & 666.79 & - & $8.54 \%$ & $-40 \%$ \\
\hline $\mathbf{0 1 . 0 3 . 2 0 0 8}$ & 1322,7 & 1330.45 & 1359.68 & 1256.98 & - & $-0.60 \%$ & $-7 \%$ \\
\hline $\mathbf{0 1 . 0 3 . 2 0 0 7}$ & 1420,86 & 1406.80 & 1438.89 & 1363.98 & - & $1.00 \%$ & $10 \%$ \\
\hline $\mathbf{0 1 . 0 3 . 2 0 0 6}$ & 1294,83 & 1280.66 & 1310.88 & 1268.42 & - & $1.11 \%$ & $10 \%$ \\
\hline $\mathbf{0 1 . 0 3 . 2 0 0 5}$ & 1180,59 & 1203.60 & 1229.11 & 1163.69 & $--1.91 \%$ & $5 \%$ \\
\hline $\mathbf{0 1 . 0 3 . 2 0 0 4}$ & 1126,21 & 1144.94 & 1163.23 & 1087.06 & $--1.64 \%$ & $33 \%$ \\
\hline $\mathbf{0 1 . 0 3 . 2 0 0 3}$ & 848,18 & 841.15 & 895.90 & 788.90 & $1,50 \mathrm{~B}$ & $\mathbf{0 . 8 4 \%}$ & $-26 \%$ \\
\hline $\mathbf{0 1 . 0 3 . 2 0 0 2}$ & 1147,39 & 1106.73 & 1173.94 & 1106.73 & $1,39 \mathrm{~B}$ & $3.67 \%$ & $-1 \%$ \\
\hline $\mathbf{0 1 . 0 3 . 2 0 0 1}$ & 1160,33 & 1239.94 & 1267.42 & 1081.19 & $1,32 \mathrm{~B}$ & $-6.42 \%$ & $-23 \%$ \\
\hline $\mathbf{0 1 . 0 3 . 2 0 0 0}$ & 1498,58 & 1366.42 & 1552.87 & 1346.62 & $1,19 \mathrm{~B}$ & $9.67 \%$ & $16 \%$ \\
\hline $\mathbf{0 1 . 0 3 . 1 9 9 9}$ & 1286,37 & 1238.33 & 1323.82 & 1216.03 & $822,90 \mathrm{M}$ & $3.88 \%$ & $17 \%$ \\
\hline $\mathbf{0 1 . 0 3 . 1 9 9 8}$ & 1101,75 & 1049.34 & 1113.07 & 1030.87 & $654,30 \mathrm{M}$ & $4.99 \%$ & $46 \%$ \\
\hline $\mathbf{0 1 . 0 3 . 1 9 9 7}$ & 757,12 & 790.82 & 814.90 & 756.13 & $533,83 \mathrm{M}$ & $-4.26 \%$ & $17 \%$ \\
\hline $\mathbf{0 1 . 0 3 . 1 9 9 6}$ & 645,5 & 640.43 & 656.97 & 627.63 & $447,51 \mathrm{M}$ & $\mathbf{0 . 7 9} \%$ & $29 \%$ \\
\hline $\mathbf{0 1 . 0 3 . 1 9 8 6}$ & 238,9 & 226.92 & 240.11 & 222.18 & $167,45 \mathrm{M}$ & $5.28 \%$ & $9,2 \%$ \\
\hline & & & & & & \\
\hline
\end{tabular}


3 - Risco Brasil

\begin{tabular}{|l|r|}
\hline Data & $\begin{array}{l}\text { EMBI }+ \\
\text { Risco- }\end{array}$ \\
Brasil
\end{tabular}

4 - Consumo de eletricidade

\begin{tabular}{|c|c|c|c|c|c|c|}
\hline \multirow{2}{*}{ Discriminação } & \multirow{2}{*}{2015} & \multirow{2}{*}{2019} & \multirow{2}{*}{2024} & 2014-2019 & 2019-2024 & 2014-2024 \\
\hline & & & & \multicolumn{3}{|c|}{ Variação (\% a.a.) } \\
\hline $\begin{array}{l}\text { PIB } \\
\text { (R\$ bilhões de 2010) }\end{array}$ & 3.959 & 4.378 & 5.465 & 1,8 & 4,5 & 3,2 \\
\hline $\begin{array}{l}\text { População Residente } \\
\text { (10 } 10^{3} \text { habitantes) }\end{array}$ & 205.266 & 211.368 & 217.762 & 0,8 & 0,6 & 0,7 \\
\hline $\begin{array}{l}\text { PIB per capita } \\
\text { (R\$ [2010]/hab/ano) }\end{array}$ & 19.288 & 20.712 & 25.098 & 1,0 & 3,9 & 2,5 \\
\hline $\begin{array}{l}\text { Consumo de Eletricidade } \\
\text { (TWh) }\end{array}$ & 525,3 & 616,5 & 790,9 & 3,2 & 5,1 & 4,2 \\
\hline
\end{tabular}


5 - Participação por fonte

\begin{tabular}{|c|c|c|c|c|c|c|c|c|c|}
\hline \multirow{2}{*}{ Discriminaçăo } & \multicolumn{2}{|c|}{2015} & \multicolumn{2}{|c|}{2019} & \multicolumn{2}{|c|}{2024} & 2014-2019 & 2019-2024 & 2014-2024 \\
\hline & mil tep & $\begin{array}{l}\text { Participação } \\
\text { relativa (\%) }\end{array}$ & mil tep & $\begin{array}{l}\text { Participaçäo } \\
\text { relativa (\%) }\end{array}$ & mil tep & $\begin{array}{l}\text { Participação } \\
\text { relativa (\%) }\end{array}$ & \multicolumn{3}{|c|}{ Variaçăo (\% a.a.) } \\
\hline Gás natural & 19.799 & 7,4 & 21.293 & 7,1 & 26.587 & 7,5 & 3,8 & 3,3 & 3,5 \\
\hline Carvão mineral e coque & 13.050 & 4,9 & 15.294 & 5,1 & 17.330 & 4,9 & 2,6 & 2,5 & 2,5 \\
\hline Lenha & 15.019 & 5,6 & 15.651 & 5,2 & 16.809 & 4,8 & $-1,3$ & 1,4 & 0,1 \\
\hline Carvão vegetal & 4.146 & 1,6 & 4.403 & 1,5 & 5.506 & 1,6 & 2,1 & 4,6 & 3,3 \\
\hline Bagaço de cana & 29.191 & 11,0 & 34.727 & 11,6 & 37.786 & 10,7 & 4,0 & 1,7 & 2,8 \\
\hline Eletricidade & 45.173 & 17,0 & 53.015 & 17,6 & 68.014 & 19,2 & 3,0 & 5,1 & 4,1 \\
\hline Etanol & 15.303 & 5,7 & 18.526 & 6,2 & 21.795 & 6,2 & 6,4 & 3,3 & 4,8 \\
\hline Biodiesel & 3.372 & 1,3 & 3.696 & 1,2 & 4.302 & 1,2 & 11,0 & 3,1 & 7,0 \\
\hline Outros & 6.498 & 2,4 & 9.140 & 3,0 & 11.410 & 3,2 & 5,9 & 4,5 & 5,2 \\
\hline Derivados de petróleo & 114.765 & 43,1 & 124.731 & 41,5 & 143.959 & 40,7 & 1,5 & 2,9 & 2,2 \\
\hline Óleo diesel & 48.881 & 18,4 & 53.904 & 17,9 & 63.090 & 17,8 & 2,5 & 3,2 & 2,8 \\
\hline Óleo combustivel & 3.627 & 1,4 & 4.054 & 1,3 & 4.628 & 1,3 & $-0,2$ & 2,7 & 1,3 \\
\hline Gasolina & 24.794 & 9,3 & 24.811 & 8,3 & 27.705 & 7,8 & $-0,7$ & 2,2 & 0,7 \\
\hline GLP & 8.554 & 3,2 & 9.130 & 3,0 & 9.972 & 2,8 & 1,8 & 1,8 & 1,8 \\
\hline Querosene & 3.661 & 1,4 & 4.079 & 1,4 & 5.164 & 1,5 & 2,2 & 4,8 & 3,5 \\
\hline Outros derivados de petróleo & 25.249 & 9,5 & 28.753 & 9,6 & 33.401 & 9,4 & 1,7 & 3,0 & 2,4 \\
\hline Consumo final de energia & 266.315 & 100,0 & 300.477 & 100,0 & 353.498 & 100,0 & 2,6 & 3,2 & 2,9 \\
\hline
\end{tabular}

6 - Consumo de energia por subsistema

Tabela 17 - Consumo de eletricidade na rede por subsistema

\begin{tabular}{|c|c|c|c|c|c|c|c|}
\hline \multirow{3}{*}{ Ano } & \multicolumn{4}{|c|}{ Subsistema } & \multirow{2}{*}{ SIN } & \multirow{2}{*}{$\begin{array}{l}\text { Sistemas } \\
\text { Isolados }\end{array}$} & \multirow{2}{*}{ Brasil } \\
\hline & Norte & Nordeste & Sudeste/CO & Sul & & & \\
\hline & \multicolumn{7}{|c|}{ GWh } \\
\hline 2015 & 34.177 & 72.617 & 276.678 & 85.070 & 468.542 & 2.377 & 470.918 \\
\hline 2019 & 41.625 & 84.839 & 312.820 & 95.992 & 535.276 & 2.117 & 537.393 \\
\hline 2024 & 58.598 & 110.954 & 399.410 & 119.706 & 688.668 & 3.468 & 692.137 \\
\hline Período & \multicolumn{7}{|c|}{ Variação (\% a.a.) } \\
\hline $2014-2019$ & 4,3 & 3,4 & 2,3 & 2,5 & 2,7 & $-10,9$ & 2,6 \\
\hline 2019-2024 & 7,1 & 5,5 & 5,0 & 4,5 & 5,2 & 10,4 & 5,2 \\
\hline $2014-2024$ & 5,7 & 4,4 & 3,6 & 3,5 & 3,9 & $-0,8$ & 3,9 \\
\hline
\end{tabular}
\begin{tabular}{ll}
\hline Nota: & Considera as interligaçöes de Macapá a partir de maio de 2015 e de Boavista a partir de junho de 2017 ao subsistema Norte. \\
Fonte: & EPE
\end{tabular} 


\begin{tabular}{|c|c|}
\hline Industry Name & Number of Firms \\
\hline Advertising & 44 \\
\hline Aerospace/Defense & 92 \\
\hline Air Transport & 20 \\
\hline Apparel & 63 \\
\hline \begin{tabular}{|l|} 
Auto \& Truck \\
\end{tabular} & 19 \\
\hline Auto Parts & 65 \\
\hline Bank (Money Center) & 9 \\
\hline Banks (Regional) & 644 \\
\hline Beverage (Acoholic) & 22 \\
\hline Beverage (Soft) & 43 \\
\hline Broadcasting & 29 \\
\hline Brokerage \& Investment Banking & 42 \\
\hline Building Materials & 39 \\
\hline Business \& Consumer Services & 159 \\
\hline Cable TV & 19 \\
\hline \begin{tabular}{|l|} 
Chemical (Basic) \\
\end{tabular} & 42 \\
\hline Chemical (Diversified) & 9 \\
\hline \begin{tabular}{|l|} 
Chemical (Specialty) \\
\end{tabular} & 104 \\
\hline Coal \& Related Energy & 38 \\
\hline Computer Services & 118 \\
\hline Computers/Peripherals & 64 \\
\hline Construction Supplies & 52 \\
\hline Diversified & 26 \\
\hline \begin{tabular}{|l} 
Drugs (Biotechnology) \\
\end{tabular} & 411 \\
\hline Drugs (Pharmaceutical) & 157 \\
\hline Education & 40 \\
\hline \begin{tabular}{|l|} 
Electrical Equipment \\
\end{tabular} & 120 \\
\hline Electronics (Consumer \& Office) & 25 \\
\hline Electronics (General) & 167 \\
\hline Engineering/Construction & 51 \\
\hline Entertainment & 84 \\
\hline Environmental \& Waste Services & 97 \\
\hline Farming/Agriculture & 37 \\
\hline Financial Svcs. (Non-bank \& Insuran & 272 \\
\hline Food Processing & 89 \\
\hline Food Wholesalers & 14 \\
\hline Furn/Home Furnishings & 30 \\
\hline Green \& Renewable Energy & 28 \\
\hline Healthcare Products & 254 \\
\hline \begin{tabular}{|l} 
Healthcare Support Services \\
\end{tabular} & 127 \\
\hline \begin{tabular}{|l|} 
Heathcare Information and Technol \\
\end{tabular} & 126 \\
\hline Homebuilding & 34 \\
\hline Hospitals/Healthcare Facilities & 58 \\
\hline Hotel/Gaming & 73 \\
\hline \begin{tabular}{|l} 
Household Products \\
\end{tabular} & 134 \\
\hline \begin{tabular}{|l|} 
Information Services \\
\end{tabular} & 70 \\
\hline \begin{tabular}{|l|} 
Insurance (General) \\
\end{tabular} & 20 \\
\hline Insurance (Life) & 25 \\
\hline Insurance (Prop/Cas.) & 53 \\
\hline Investments \& Asset Management & 145 \\
\hline Machinery & 130 \\
\hline Metals \& Mining & 114 \\
\hline Office Equipment \& Services & 24 \\
\hline \begin{tabular}{|l|} 
Oil/Gas (Integrated) \\
\end{tabular} & 7 \\
\hline \begin{tabular}{|l|} 
Oil/Gas (Production and Exploratio \\
\end{tabular} & 351 \\
\hline \begin{tabular}{|l|} 
Oil/Gas Distribution \\
\end{tabular} & 79 \\
\hline \begin{tabular}{|l|} 
Oilfield Svcs/Equip. \\
\end{tabular} & 143 \\
\hline Packaging \& Container & 25 \\
\hline Paperfforest Products & 20 \\
\hline Power & 73 \\
\hline Precious Metals & 173 \\
\hline Publshing \& Newspapers & 39 \\
\hline R.E.I.T. & 221 \\
\hline \begin{tabular}{|l} 
Real Estate (Development) \\
\end{tabular} & 21 \\
\hline \begin{tabular}{|l|} 
Real Estate (General/Diversified) \\
\end{tabular} & 12 \\
\hline Real Estate (Operations \& Services) & 55 \\
\hline Recreation & 65 \\
\hline Reinsurance & 3 \\
\hline RestaurantDining & 83 \\
\hline \begin{tabular}{|l} 
Retail (Automotive) \\
\end{tabular} & 26 \\
\hline Retail (Building Supply) & 5 \\
\hline \begin{tabular}{|l|} 
Retail (Distributors) \\
\end{tabular} & 83 \\
\hline Retail (General) & 19 \\
\hline \begin{tabular}{|l} 
Retail (Grocery and Food) \\
\end{tabular} & 17 \\
\hline Retail (Online) & 39 \\
\hline Retail (Special Lines) & 124 \\
\hline Rubber\& Tires & 4 \\
\hline Semiconductor & 87 \\
\hline Semiconductor Equip & 46 \\
\hline Shipbuilding \& Marine & 11 \\
\hline Shoe & 11 \\
\hline Software (Entertainment) & 17 \\
\hline Soffware (Internet) & 308 \\
\hline Software (System \& Application) & 241 \\
\hline Steel & 36 \\
\hline Telecom (Wireless) & 19 \\
\hline Telecom. Equipment & 121 \\
\hline Telecom. Services & 65 \\
\hline Tobacco & 20 \\
\hline Transportation & 21 \\
\hline Transportation (Railroads) & 12 \\
\hline Trucking & 26 \\
\hline Unclassified & 3 \\
\hline Utility (General) & 20 \\
\hline Utility (Water) & 18 \\
\hline Total Market & 7480 \\
\hline
\end{tabular}




\begin{tabular}{|l|r|r|r|r|r|r|r|r|r|r|r|r|r|r|}
\hline Índice Cobertura Dívida & $\mathbf{2 0 1 6}$ & $\mathbf{2 0 1 7}$ & $\mathbf{2 0 1 8}$ & $\mathbf{2 0 1 9}$ & $\mathbf{2 0 2 0}$ & $\mathbf{2 0 2 1}$ & $\mathbf{2 0 2 2}$ & $\mathbf{2 0 2 3}$ & $\mathbf{2 0 2 4}$ & $\mathbf{2 0 2 5}$ & $\mathbf{2 0 2 6}$ & $\mathbf{2 0 2 7}$ \\
\hline Serviço da Dívida & 255 & 242 & 230 & 218 & 205 & 193 & 181 & 169 & 156 & 144 & 132 & 119 \\
Saldo & 1.178 & 1.071 & 964 & 857 & 750 & 643 & 536 & 429 & 321 & 214 & 107 & - \\
Amortização & 107 & 107 & 107 & 107 & 107 & 107 & 107 & 107 & 107 & 107 & 107 & 107 \\
Juros & 147 & 135 & 123 & 111 & 98 & 86 & 74 & 61 & 49 & 37 & 25 & 12 \\
\hline
\end{tabular}

\begin{tabular}{|c|c|c|c|c|c|c|c|c|}
\hline Fonte & Premissas & & 2015 & 2016 & 2017 & 2018 & 2019 & 2020 \\
\hline Site RI ENEVA & Período de Concessão & anos & 15 & & & & & \\
\hline Site RI ENEVA & Capacidade Instalada & MW & 360 & 360 & 360 & 360 & 360 & 360 \\
\hline Site RI ENEVA & Garantia Física & $\mathrm{MWm}$ & 340 & 340 & 340 & 340 & 340 & 340 \\
\hline Site RI ENEVA & Energia Assegurada & MW & 315 & 315 & 315 & 315 & 315 & 315 \\
\hline ITR ENEVA 4T15 & ACR & & & & & & & \\
\hline ITR ENEVA 4T15 & $\mathrm{ACL}$ & & & & & & & \\
\hline \multicolumn{2}{|c|}{ Nymex (preço do carv CVUcom } & $(\mathrm{R} \$ / \mathrm{MWh})$ & 103,1 & 99,1 & 90,2 & 90,4 & 88,6 & 90,6 \\
\hline \multicolumn{2}{|c|}{ Leilão A-5 2013 - ITR E CVUo\&m } & $(\mathrm{R} \$ / \mathrm{MWh})$ & 18,8 & 20,2 & 21,3 & 22,7 & 24,1 & 25,7 \\
\hline ITR ENEVA 4T15 & Receita Fixa & $\mathrm{R} \$ \mathrm{~mm} / \mathrm{ano}$ & 359,2 & 385,3 & 407,1 & 433,4 & 461,4 & 491,2 \\
\hline
\end{tabular}

http://www.multpl.cc UST Bond 20 anos (média 1996-2016) - Rf $\quad 4,63 \%$

http://br.investing.co (S\&P 500) (média 1996-2016) - Rm 9,2\%

\begin{tabular}{|llc|}
\hline \multicolumn{2}{|c|}{ Banco } & $70 \%$ \\
http://www.ipeadata & Risco País (Rb) EMBI+Risco Brasil & $4,8 \%$ \\
\hline http://pages.stern.ny $\beta$ & 1,52 \\
\hline BALANÇO ITR 4T15 & PIS/COFINS/P\&D & $10,3 \%$ \\
Banco Central (Focus) IPCA & $9,3 \%$ \\
BALANÇO ITR 4T15 & Depreciação & 200,0 \\
BALANÇO ITR 4T15 & Capital Próprio & $30 \%$ \\
BALANÇO ITR 4T15 & Capital de Terceiros & $70 \%$ \\
& Investimento Inicial & 2200 \\
Média das dívidas de ICusto de Capital de Terceiros & $11 \%$ \\
\hline
\end{tabular}

\begin{tabular}{l|r|}
\hline CAPM Conversão & $4,5 \%$ \\
\hline MÉDIA IPCA 1996-2016 & $6,78 \%$ \\
MÉDIA INFLAÇÃO EUA & $2,19 \%$ \\
\hline Custo de Capital Próprio & CAPM \\
\hline Ke=Rf+ $\beta($ Rm-Rf)+Rb+(1+iBr $/ 1+$ ieua $)$ & $20,84 \%$ \\
\hline
\end{tabular}

\begin{tabular}{|c|c|c|c|c|c|}
\hline IPCA & 2016E & 2017E & 2018E & 2019E & 2020E \\
\hline Focus (Banco Central) & $7,26 \%$ & $5,66 \%$ & $6,46 \%$ & $6,46 \%$ & $6,46 \%$ \\
\hline \multicolumn{6}{|c|}{ 'Focus Relatório de Mercado semanal de setembro de 2015 (04/11/2015) } \\
\hline \multicolumn{6}{|c|}{${ }^{2}$ Focus Relatório de Mercado semanal de março de 2016 (04/03/2016) } \\
\hline \multicolumn{6}{|c|}{${ }^{3}$ Média aritmética dos dois últimos dados fornecidos pelo Relatório do Focus } \\
\hline
\end{tabular}




\section{Bibliografia}

ALBRECHT, C. Análise avançada da classificação de indicadores contábeis-financeiros e de mercado aplicados para a avaliação de ações. Universidade do Rio Grande do Sul, 2011.

ANEEL (Agência Nacional de Energia Elétrica). BIG (Banco de Informações de Geração), 2016. Capacidade de Geração no Brasil. Disponível em: <http://www.aneel.gov.br/aplicacoes/capacidadebrasil/capacidadebrasil.cfm> Acesso em 12/11/2015.

Associação Brasileira de Geradoras Termelétricas, 2016. Institucional Estatuto Social. Disponível em: <http://www.abraget.com.br/zpublisher/materias/Institucional.asp?id=16322> Acesso em 12/11/2015.

Autor desconhecido. ISTO É Dinheiro, 2015. EDP comemora compra de Pecém por valor inferior a venda de Pantanal. Disponível em: $<$ http://www.istoedinheiro.com.br/noticias/negocios/20150730/edp-comemoracompra-pecem-por-valor-inferior-venda-pantanal/284929.shtml> Acesso em: 10/11/2015.

Autor desconhecido. Visão Geral do Setor. Disponível em: <http://www.abradee.com.br/setor-eletrico/visao-geral-do-setor> Acesso em: 10/02/2016.

DAMODARAN, A. Beta dos ativos. Cost os Capital by Sector, January, 2016. Disponível em: <http://pages.stern.nyu.edu/ adamodar/New_Home_Page/datafile/wacc.htm> Acesso em: 15/05/2016

DAMODARAN, A. Avaliação de investimentos, $3^{\text {a }}$ reimpressão. Ferramentas e técnicas para avaliação do valor de qualquer ativo. Editora: Qualitymark, 2011.

Empresa de Pesquisa Energética, 2016. Plano Decenal de expansão de energia. Disponível em: <http://www.epe.gov.br/PDEE/Relat\%C3\%B3rio\%20Final\%20do\%20PDE\%2020 24.pdf> Acesso em: 25/11/2015.

ENDLER, L. UFRGS, 2004. Avaliação de empresas pelo método de FCD e os desvios causados pela utilização de taxas de desconto inadequadas. Disponível em: <http://seer.ufrgs.br/index.php/ConTexto/article/view/11715/6918> Acesso em: $11 / 11 / 2015$.

ENEVA. Relações Internacionais. Release de Resultados. Divulgação de Resultado 4T15/ 4T14/ 4T13. Disponível em: < http://ri.eneva.com.br/> Acesso em: $15 / 02 / 2016$ 
FERNANDES, D. Revista da FAE, 2004. Uma contribuição sobre a construção de indicadores e sua importância para a gestão empresarial. Disponível em:

http://www.fae.edu/publicacoes/pdf/revista_da_fae/fae_v7_n1/rev_fae_v7_n1_01 _dejair.pdf> Acesso em: 31/03/2016.

Inflação Brasil (CAPM). Instituto Brasileiro de Geografia e Estatística (IBGE). Disponível em: <http://www.ibge.gov.br/home/estatistica/indicadores/precos/inpc_ipca/defaultseri esHist.shtm> Acesso em: 06/06/2016

Inflação Estados Unidos (CAPM). US Inflation calculator. Disponível em: $<$ http://www.usinflationcalculator.com/inflation/historical-inflation-rates/> Acesso em: 06/06/2016

KUHN, I., LAMPERT, A.. Análise Financeira. Editora: Unijuí da Universidade Regional Noroeste, 2012.

LIMA, M, SOUZA, M. Revista do Centro de Ciências Naturais e Exatas - UFSM. Discorrendo sobre o uso das Termelétricas no Brasil. Disponível em: http://cascavel.ufsm.br/revistas/ojs-

2.2.2/index.php/cienciaenatura/article/viewFile/18493/pdf. Acesso em: 11/11/15.

MATARAZZO, C. Análise Financeira de Balanços. Editora: Atlas, 2003.

GIL.UNISANTA. 2010. Metodologia de Pesquisa. Disponível em: <http://cursos.unisanta.br/civil/arquivos/Pesquisa_Cientifica_metodologias.pdf> Acesso em: 09/11/2015.

NETO, A. Instituto Assaf Neto, 2007. Uma proposta metodológica para o cálculo do custo de capital no Brasil. Disponível em: $<$ http://www.institutoassaf.com.br/downloads/artigo_rausp_custo_capital_no_bra sil.pdf> Acesso em: 28/03/2016

NETO, A. Instituto Assaf Neto, 2013. Superioridade do método de Fluxo de Caixa Descontado. Disponível em: < http://www.institutoassaf.com.br/downloads/SUPERIORIDADE_M\%C3\%89TOD O_FLUXO_CAIXA_DESCONTADO_PROCESSO_AVALIA $\%$ C $3 \% 87 \%$ C $3 \% 830$ _ EMPRESAS.pdf> Acesso em: 11/11/2015.

OLIVEIRA, R.. Análise financeira e econômica por meio de indicadores das demonstrações contábeis: um estudo de caso em uma empresa de consultoria ambiental. Academia do curso de Ciências Contábeis Faculdade de Minas, 2013.

POVOA, A.. Valuation, como precificar ações. Editora: Elsevier Editora LTDA., 2012.

Preço do carvão (US\$/ Ton). CME Group, 2016. Coal (API2) CIF ARA (ARGUSMcCloskey) Futures Quotes. Disponível em: < http://www.cmegroup.com/trading/energy/coal/coal-api-2-cif-ara-argusmccloskey.html> Acesso em: 13/03/2016

Relações com investidores. Eneva, 2013. UTE Itaqui, da MPX, começa a operar. Disponível em: <http://www.Eneva.com.br/pt/sala-de- 
imprensa/noticias/Paginas/UTE-Itaqui,-da-MPX,-inicia-operacao-comercial.aspx> Acesso em: 21/11/2015.

Relações com investidores. Eneva, 2016. Empreendimentos Eneva. Disponível em: <http://ri.eneva.com.br/conteudo_pt.asp?idioma=0\&conta=28\&tipo=57771> Acesso em: 25/03/2016.

Risco País. EMBI + Risco Brasil. JP Morgan. Ipea Data, 2016. Disponível em: $<$ http://www.ipeadata.gov.br/ExibeSerie.aspx?serid=40940\&module=M $>$ Acesso em: $22 / 03 / 2016$

ROSS, S., WESTERFIELD, R., JORDAN, D. Princípios de administração financeira, segunda edição. Editora: Atlas, 2011.

SALVADOR, A.. CMU Energia, 2011. Termelétrica ociosa fatura mais. Disponível em:

http://www.cmuenergia.com.br/site/Noticia/Termeletrica_ociosa_fatura_mais/110 > Acesso em: 16/03/2016.

SAURIN, L., LOPES, A., JUNIOR, N. SCIELO, 2009. Comparação dos modelos de avaliação de empresas com base no fluxo de caixa descontado e no lucro residual: Estudo de Caso de uma empresa de energia elétrica. Disponível em: <http://www.scielo.br/pdf/ram/v10n1/v10n1a05.pdf> Acesso em: 27/11/2015.

Sociedade Brasileira de Planejamento Energético (SBPE). Perspectivas para a geração termelétrica a carvão. Revista Brasileira de Energia Vol.12 | No 2.

S\&P 500 Dados históricos. 20 anos (média 1996-2016). Investing. Disponível: < http://br.investing.com/indices/us-spx-500-historical-data> Acesso em: 15/05/2016.

Taxa de câmbio. Banco Central, 2016. Focus - Relatório de Mercado. Disponível em: < http://www.bcb.gov.br/pec/GCI/PORT/readout/R20150904.pdf> Acesso em: 30/03/2016.

US Bond 20 anos (média 1996-2016). 20 Year Treasury Rate by Year. Disponível em: < http://www.multpl.com/20-year-treasury-rate/table> Acesso em: 15/05/2016.

VIEIRA, Xisto. 2015. Negócios e Petróleo. Abraget defende a análise criteriosa para geração de energia térmica a gás natural liquefeito. Disponível em: <http://negociosepetroleo.com/2015/09/09/abraget-defendeanalise-criteriosa-para-geracao-de-energia-termica-a-gas-natural-liquefeito-gnl/> Acesso em: 15/11/2015. 